\title{
Neonatal Stroke and TLR1/2 Ligand Recruit Myeloid Cells through the Choroid Plexus in a CX3CR1-CCR2- and Context-Specific Manner
}

\author{
Aditya Rayasam, Joel Faustino, Matthieu Lecuyer, and Zinaida S. Vexler \\ Department of Neurology, University of California San Francisco, San Francisco, California 94158
}

Neonatal stroke is as frequent as stroke in the elderly, but many pathophysiological injury aspects are distinct in neonates, including immune signaling. While myeloid cells can traffic into the brain via multiple routes, the choroid plexus (CP) has been identified as a uniquely educated gate for immune cell traffic during health and disease. To understand the mechanisms of myeloid cell trafficking via the $\mathrm{CP}$ and their influence on neonatal stroke, we characterized the phenotypes of $\mathrm{CP}$-infiltrating myeloid cells after transient middle cerebral artery occlusion (tMCAO) in neonatal mice of both sexes in relation to blood-brain barrier permeability, injury, microglial activation, and CX3CR1-CCR2 signaling, focusing on the dynamics early after reperfusion. We demonstrate rapid recruitment of multiple myeloid phenotypes in the $\mathrm{CP}$ ipsilateral to the injury, including inflammatory

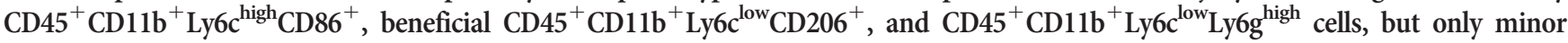
leukocyte infiltration into acutely ischemic-reperfused cortex and negligible vascular albumin leakage. We report that CX3CR1CCR2-mediated myeloid cell recruitment contributes to stroke injury. Considering the complexity of inflammatory cascades triggered by stroke and a role for TLR2 in injury, we also used direct TLR2 stimulation as an independent injury model. TLR2 agonist rapidly recruited myeloid cells to the $\mathrm{CP}$, increased leukocytosis in the CSF and blood, but infiltration into the cortex remained low over time. While the magnitude and the phenotypes of myeloid cells diverged between TMCAO and TLR2 stimulation, in both models, disruption of CX3CR1-CCR2 signaling attenuated both monocyte and neutrophil trafficking to the CP and cortex.

Key words: immune; inflammation; ischemia; microglia; perinatal

\section{Significance Statement}

Stroke during the neonatal period leads to long-term disabilities. The mechanisms of ischemic injury and inflammatory response differ greatly between the immature and adult brain. We examined leukocyte trafficking via the choroid plexus $(\mathrm{CP})$ following neonatal stroke in relation to blood-brain barrier integrity, injury, microglial activation, and signaling via CX3CR1 and CCR2 receptors, or following direct TLR2 stimulation. Ischemia-reperfusion triggered marked unilateral CX3CR1-CCR2 dependent accumulation of diverse leukocyte subpopulations in the CP without inducing extravascular albumin leakage or major leukocyte infiltration into the brain. Disrupted CX3CR1-CCR2 signaling was neuroprotective in part by attenuating monocyte and neutrophil trafficking. Understanding the migratory patterns of $\mathrm{CP}$-infiltrating myeloid cells with intact and disrupted CX3CR1-CCR2 signaling could identify novel therapeutic targets to protect the neonatal brain.

Received Sep. 3, 2019; revised Feb. 25, 2020; accepted Feb. 26, 2020

Author contributions: A.R. and Z.S.V. designed research; A.R., J.F., and M.L. performed research; A.R. and Z.S.V. analyzed data; A.R. and Z.S.V. wrote the first draft of the paper; A.R. and Z.S.V. edited the paper; A.R. and Z.S.V. wrote the revised paper.

The work was supported by National Institutes of Health R01 NS44025, R01 NS76726, R21 NS98514, and R01 NS103483 to Z.S.V. We thank Dr. Oleg Butovsky (Harvard Medical School) for providing P2RY12 and 4D4 antibodies; and Jessica Santhakumar and Amy Jung for contributing to cryostat sectioning and infarct volume analyses.

The authors declare no competing financial interests.

Correspondence should be addressed to Zinaida S. Vexler at Zena.Vexler@ucsf.edu.

https://doi.org/10.1523/JNEUROSCI.2149-19.2020

Copyright $(2) 2020$ the authors

\section{Introduction}

Ischemic brain damage during the neonatal period can result in severe long-term cognitive deficits, including cerebral palsy, cognitive decline, and epilepsy (Nelson and Lynch 2004; Nelson, 2007; Raju et al., 2007; Ferriero et al., 2019). While the incidence of stroke is similar in neonates and adults, there is now ample evidence that the mechanisms of ischemic injury differ greatly between neonatal and adult brain, including blood-brain barrier (BBB) and neuroimmune responses (Fernandez-Lopez et al., 2014; Hagberg et al., 2015). For example, albumin leakage is profound after acute transient middle cerebral artery occlusion (tMCAO) in adult rodents, whereas leakage is low after tMCAO in neonatal rodents (Fernandez-Lopez et al., 2012). The ischemic 
brain environment can activate local microglial cells and induce infiltration of peripheral leukocytes into the brain in both adult and neonatal stroke, with immune cells playing an array of beneficial and injurious roles (Iadecola and Anrather 2011; Fumagalli et al., 2015; Hagberg et al., 2015; Garcia-Bonilla et al., 2016; Mallard et al., 2018, 2019; Cserép et al., 2020). Nonetheless, transcriptomics have highlighted the phenotypic changes in myeloid cells and microglia from development to adulthood, suggesting that their role in stroke pathology may be age-dependent (Butovsky et al., 2014; Grassivaro et al., 2020).

Under physiological conditions, peripheral immune cells are essentially prevented from CNS entry by the presence of the surrounding barrier systems: the $\mathrm{BBB}$, the meningeal barrier and the choroid plexus (CP); the latter that forms the barrier between blood and CSF (Prinz and Priller 2017). Recently, the CP has been identified as a major gate for leukocyte trafficking, orchestrating immune responses under physiological and neurodegenerative conditions (Saunders et al., 2018). The CP can sense signals within the CSF to alert circulating immune cells to respond via cytokine receptors (Engelhardt and Sorokin 2009; Kunis et al., 2013; Schwartz and Baruch 2014). Furthermore, the CP exerts important barrier and homeostatic functions by mediating CSF turnover/flow and influx/efflux transporters (Engelhardt and Sorokin 2009; Schwartz and Baruch 2014), with CP macrophages providing surveillance of CSF production under steady-state conditions (Prinz and Priller 2017). Changes of the cytokine milieu within the $\mathrm{CP}$ can recruit anti-inflammatory myeloid cells into damaged brain areas to resolve inflammation as well, as demonstrated after traumatic brain injury (Szmydynger-Chodobska et al., 2012) and spinal cord injury (Shechter et al., 2013).

It has become clear that unsynchronized development of individual CNS barriers affects vulnerability of the immature brain to ischemic, excitotoxic, and oxidative damage (Mallard et al., 2018). The CP undergoes major changes during development and by adulthood (Saunders et al., 2018, 2000), resulting in brain maturation-specific and trigger-specific patterns of leukocyte infiltration into the injured brain (Ek et al., 2010; Liddelow et al., 2012; Kunis et al., 2013). In neonates, distinct Toll-like receptor (TLR) type-dependent inflammatory cytokine "signatures" and leukocyte phenotypes were recently demonstrated by markedly higher monocyte and neutrophil transmigration via the $\mathrm{CP}$ after Pam3CSK4 (PAM)-induced TLR2 stimulation than after LPSinduced TLR4 stimulation (Mottahedin et al., 2017, 2019). The role for TLR2 was demonstrated in neonatal stroke (LalancetteHebert et al., 2017).

Considering that the CP may serve as a potential therapeutic target, we examined leukocyte trafficking via the $\mathrm{CP}$ and into the neonatal brain following tMCAO in relation to BBB integrity, injury, microglial activation, and CX3CR1-CCR2 signaling. We describe rapid marked unilateral accumulation of both beneficial and inflammatory leukocyte phenotypes in the $\mathrm{CP}$, effects that are not associated with extravascular albumin leakage or major leukocyte infiltration into the brain, and demonstrate that the magnitude of myeloid cell accumulation in the CP and injury after tMCAO depend on CX3CR1-CCR2 signaling. Utilization of a second, and a more simple model, direct TLR2 stimulation, to further elucidate the dynamics and phenotypic characteristics of immune cell passage via the $\mathrm{CP}$, revealed distinct immune phenotypes in the $\mathrm{CP}$ early and further divergence over time, yet leukocyte trafficking via $\mathrm{CP}$ and microglial activation depend on CX3CR1-CCR2 signaling in both models.

\section{Materials and Methods}

\section{Animals}

All research conducted on animals was approved by the University of California San Francisco Institutional Animal Care and Use Committee and in accordance to the Guide for the care and use of laboratory animals (U.S. Department of Health and Human Services). Animals were given ad libitum access to food and water, housed with nesting material and shelters, and kept in rooms with temperature control and light/dark cycles. The data are in compliance with the ARRIVE guidelines (Animal Research: Reporting in Vivo Experiments). Block litter design and randomization within individual litters were used. Blinded data analysis was used where possible.

tMCAO was performed on postnatal day 9 (P9)-P10 C57BL/6 WT (purchased from Charles River) mice of both sexes, as we previously described (Woo et al., 2012). Briefly, a midline cervical incision was made under isoflurane anesthesia, the common carotid artery and internal carotid artery exposed, single threads from a 7-0 silk suture used to temporary tie a knot below the origin of the internal carotid artery to prevent retrograde bleeding from the arteriotomy. A coated 8-0 nylon suture was advanced $4-5 \mathrm{~mm}$ and removed $3 \mathrm{~h}$ later. In sham-operated pups, suture was inserted but not advanced. Mice from the same litters were randomized to receive $\mathrm{tMCAO}$ or sham surgery. Temperature was maintained with temperature-controlled blanket and overhead lamp. tMCAO was performed on CX3CR $1^{\mathrm{GFP} /+} / \mathrm{CCR} 2^{\mathrm{RFP} /+}$ mice (referred in the text as ${ }^{\mathrm{GFP} /+} /{ }^{\mathrm{RFP} /+}$ ), $\mathrm{CX} 3 \mathrm{CR} 1^{\mathrm{GFP} / \mathrm{GFP}} / \mathrm{CCR} 2^{\mathrm{RFP} / \mathrm{RFP}}$ mice (referred in the text as GFP/GFP/RFP/RFP) and WT mice, all on C57Bl/6 background. The GFP/GFP/RFP/RFP mouse line was established at Charo's laboratory at the Gladstone Institute at the University of California San Francisco (Saederup et al., 2010); founders for the colony were provided to us by Dr. Katerina Akassoglou at the Gladstone Institutes at the University of California San Francisco. Based on our historic diffusion-weighted MRI data in the model and the presence of recirculation on suture removal, as evident using intrajugular injection of FITC-isolectin B4 (Woo et al., 2012; Fernandez-Lopez et al., 2016; Chip et al., 2017), the incidence of injury is $>70 \%$ and no bleeding associated with reperfusion. The apparent presence of cleaved caspase- 3 in brain lysates and gross injury starting at $3 \mathrm{~h}$ after reperfusion served as inclusion/exclusion criteria, described in detail previously (Wendland et al., 2008; Woo et al., 2012). Data for male and female pups were combined based on our published data on similar injury in male and female pups at $72 \mathrm{~h}$ (Chip et al., 2017) and unpublished data for outcomes at 1-4 weeks of reperfusion in several mouse lines on C57BL/6 background.

Pam3CSK4 (PAM). $5 \mathrm{mg} / \mathrm{kg}$ Pam3CSK4 (5 $\mu \mathrm{l} / \mathrm{g}$ body weight; Invivogen) was administered intraperitoneally to P9-P10 C57BL/6 WT mice of both sexes.

Histology and immunofluorescence. Animals were perfused and postfixed with 4\% PFA. Postfixed, cryoprotected, and flash-frozen brains were sectioned on a cryostat (12- $\mu \mathrm{m}$-thick serial sections, $360 \mu \mathrm{m}$ apart) and injury determined in six coronal Nissl-stained sections in blinded manner by 3 study participants (J.F., J.S., and A.J.). Double immunofluorescence was performed on adjacent sections blocked in 10\% NGS/PBST and incubated overnight in $2 \%$ NGS/PBST with rabbit anti-mouse GLUT-1 (1:500, Abcam), rabbit anti-mouse TMEM119 (ED1; 1:500, Abcam), rat anti-mouse 4D4 (1:3000, Butovsky Laboratory), and rabbit anti-mouse P2RY12 (1:1000 Butovsky Laboratory) followed by an appropriate secondary antibodies purchased from Invitrogen and DAPI. P2RY12 and 4D4 antibodies were provided by Oleg Butovsky (Harvard Medical School). $z$ stacks of 14-18 images were captured at $1.0 \mu \mathrm{m}$ intervals $(25 \times / 100 \times$ oil objectives, Carl Zeiss Axiovert 100 equipped with Volocity Software, Improvision/PerkinElmer) and analysis performed in 4-5 FOVs per hemisphere/region in the ischemic-reperfused cortex and matching contralateral tissue using automated protocols for signal intensity threshold ( $>2$ SD background in each channel) in a $1 \times 10^{6} \mu \mathrm{m}^{3}$ voxel.

Myeloid cell isolation. Mice deeply anesthetized with isoflurane were transcardially perfused with cold PBS, red blood cells were lysed using 


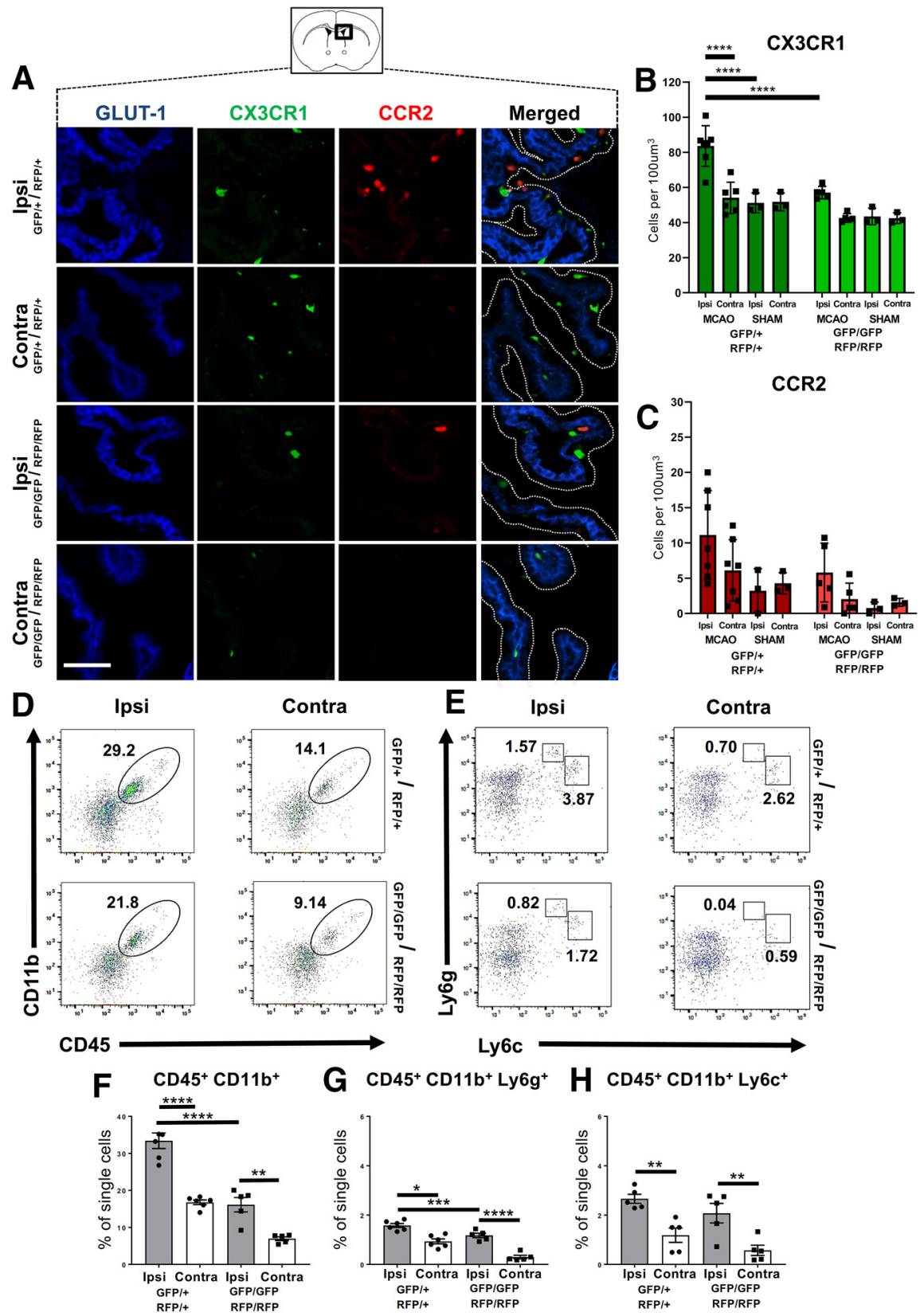

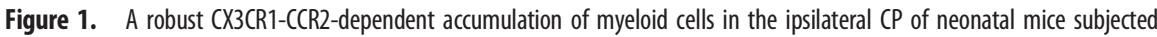
to $\mathrm{TMCAO}$ followed by $3 \mathrm{~h}$ of reperfusion. $A$, Representative images of GLUT-1-immunostained CPs ipsilateral and contralateral to $\mathrm{TMCAO}$ in ${ }^{\mathrm{GFP} /+}{ }^{\text {RFP/+ }}$ and ${ }^{\text {GFP/GFP } / \text { RFP/RFP }}$ mice. Scale bar, $50 \mu \mathrm{m}$. Dashed white lines indicate areas where cells were counted. Black box on histologic section represents where images were taken. $\boldsymbol{B}, \boldsymbol{C}$, Quantification of the number of GFP ${ }^{+}$cells $(B)$ and RFP ${ }^{+}$cells $(C)$ in ipsilateral and contralateral $C P$ s from ${ }^{\text {GFP/+ }} /{ }^{\text {RFP/+ }}$ and ${ }^{\text {GFP/GFP }} /{ }^{R F P / R F P}$ mice subjected to tMCAO or sham surgery. $\mathbf{D}-\boldsymbol{H}$, Characterization of myeloid cells from dissociated CPs by flow cytometry. Gating strategy to identify $\mathrm{CD}^{+} 5^{+} \mathrm{CD} 11 \mathrm{~b}^{+}$cells $(\boldsymbol{D})$ and $\mathrm{CD}_{4} 5^{+} 11 \mathrm{~b}^{+} \mathrm{Ly}_{6 \mathrm{~g}}{ }^{+}$and $\mathrm{CD} 45^{+} 11 \mathrm{~b}^{+} \mathrm{Ly} 6 \mathrm{c}^{+}$cells $(\boldsymbol{E})$ from ipsilateral and contralateral $\mathrm{CPs}$ of GFP/+ $/{ }^{R / P /+}$ mice (top row) and ${ }^{\text {GFP/GFP } / R F P / G F P ~}$ mice (bottom row). $\boldsymbol{E}$, Data originate from $\mathrm{CD}^{\mathrm{R}} 5^{+} \mathrm{CD} 11 \mathrm{~b}^{+}$gate in $\boldsymbol{D}$. $\boldsymbol{F}-\boldsymbol{H}$.

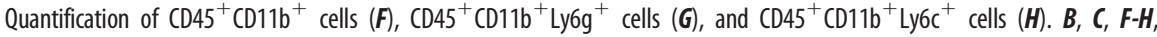
${ }^{*} p<0.05 ;{ }^{* *} p<0.01 ;{ }^{* * *} p<0.001 ;{ }^{* * *} p<0.0001$; two-way ANOVA with Tukey's Multiple Comparison post hoc test.

ACK lysis buffer, and cells were washed with RPMI. Brain and CP tissue were minced with razor blades and pushed through $70 \mu \mathrm{m}$ nylon cell strainers, incubated in $1 \mathrm{mg} / \mathrm{ml}$ collagenase for $45 \mathrm{~min}$ at $37^{\circ} \mathrm{C}$ inverted frequently. Cells were washed, resuspended in $70 \%$ Percoll, and overlaid with $30 \%$ Percoll. The cells were centrifuged at $2400 \mathrm{rpm}$ for $30 \mathrm{~min}$ at $4^{\circ} \mathrm{C}$ without brake and washed before plating.

Flow cytometry. Single-cell myelin-free suspensions from contralateral and injured regions were plated $(5 \times 105 / 96$ well), centrifuged, pellet resuspended in $100 \mu \mathrm{l}$ blocking buffer containing CD16/32 (1:70, Biolegend), and incubated in $150 \mu \mathrm{l} \mathrm{FACS}$ staining buffer containing $2 \%$
FBS. For intracellular cytokine staining, cells were fixed (Fixation and Permeabilization kit, BD Bioscience), incubated with antibody mixture on ice for $20 \mathrm{~min}$, washed, centrifuged, resuspended in staining buffer, and evaluated on BD LSRII flow cytometer (BD Biosciences). Fluorescence Minus One samples, a commonly used strategy to prevent false-positive results through overlap of fluorophores (Aghaeepour et al., 2013), was applied. The following combinations of antibodies diluted 1:200 in FACS staining buffer were used: anti-CD45-Pacific Blue (Biolegend), anti-CD11b-APC-Cy7 (Biolegend), Ly6g (IA8)-AF700 (Biolegend), Ly6c (Hk1.4)APC (Biolegend), CD206-FITC (Biolegend), IL-10-PE-Cy7 (Biolegend), CD86-FITC (Biolegend), IL-1 $\beta$-PE (Biolegend), TLR2-PEVio615 (Miltenyi Biotec). CXCR2-PE-Cy7 (Biolegend), and CCR2-PE (Biolegend). Compensation beads (BD CompBeads) were incubated in Fixation and Permeabilization solution $\left(100 \mu \mathrm{l}, 4^{\circ} \mathrm{C}, 20 \mathrm{~min}\right)$, incubated with antibody mixture $\left(4^{\circ} \mathrm{C}, 30 \mathrm{~min}\right)$, and resuspended in staining buffer. Gating and data analysis were performed using FlowJo software (Tree Star).

Multiplex cytokine assay. Protein concentrations of IL- $1 \alpha$, IL- $1 \beta$, IL-4, IL-6, IL-10, KC, MCP- 1 , and MIP- $1 \alpha$ were measured in whole-brain homogenates from injured and matching contralateral regions (Millipore), as we previously reported (Woo et al., 2012). Measurements were performed using BioPlex System (Bio-Rad) and StatLIA software (Brendan Scientific) with a 5-parameter logistic curve fitting. The data were normalized to protein concentration in the same brain homogenate sample.

Experimental design and statistical analysis. Block litter design was used to avoid litter to litter variability, randomization for tMCAO/sham was used where possible, data for all figures were obtained on unsexed neonatal mice, and injury analysis was performed in a blinded manner. Sampling for tissue sections for each mouse was performed in 4-5 FOV per hemisphere on multiple coronal sections for Figures 1-3, 5, 6, and 9 . Each dot on all graphs represents an individual mouse. Two-way ANOVA with post hoc Tukey's Multiple Comparison test was performed for comparing groups with multiple variables, as described in legends to individual figures. Student's $t$ test with MannWhitney $U$ test was performed to compare two groups, as described in legends to individual figures. GraphPad Prism 8 software was used to generate statistical data. Differences were considered significant at $p<$ 0.05 . Results are shown as mean \pm SEM.

\section{Results}

tMCAO in neonatal mice triggers rapid CX3CR1-CCR2dependent accumulation of myeloid cells in the $\mathrm{CP}$ ipsilateral to the occlusion

In several animal models of neurodegenerative diseases, including models of multiple sclerosis and stroke, recruitment of 
myeloid cells via the CP in adult mice has been shown to modify injury (Baruch and Schwartz 2013; Herz et al., 2017). To evaluate whether neonatal stroke induces accumulation of myeloid cells in the $\mathrm{CP}$, we first performed immunohistochemistry and quantified the number of $\mathrm{CX} 3 \mathrm{CR} 1^{+}$ and $\mathrm{CCR} 2^{+}$cells in the ipsilateral and contralateral CPs at $3 \mathrm{~h}$ after reperfusion in mice with functional CX3CR1 and CCR2 receptors ( $\mathrm{GFP} /+/ \mathrm{RFP} /+$ mice). We focused on an early time point based on data that leukocytes can rapidly accumulate in the neonatal CP after induction of inflammation (Mottahedin et al., 2019). In the CP demarcated by GLUT1 (Fig. 1A), the number of $\mathrm{GFP}^{+}$cells (Fig. $1 B$ ) and $\mathrm{RFP}^{+}$cells (Fig. 1C) was significantly increased ipsilateral to the occlusion compared with that in the contralateral $\mathrm{CP}$ and in CPs of sham-operated pups. In mice with disrupted CX3CR1-CCR2 signaling (GFP/GFP/RFP/RFP mice), accumulation of both CX3CR1 $1^{\text {GFP/GFP }}$ cells and $\mathrm{CCR} 2^{\mathrm{RFP} / \mathrm{RFP}}$ cells was significantly attenuated (Fig. 1B,C). These data demonstrate that accumulation of myeloid cells in the ipsilateral CP early after neonatal tMCAO depends on CX3CR1CCR2 signaling.

We then used flow cytometry to characterize the number and phenotypes of $\mathrm{CD} 45^{+} \mathrm{CD} 11 \mathrm{~b}^{+}$myeloid cells in isolated CPs at $3 \mathrm{~h}$ after reperfusion (Fig. $1 D$ ). In preliminary experiments, we determined that the patterns of $\mathrm{CD}_{4} 5^{+} \mathrm{CD} 11 \mathrm{~b}^{+}$expression are similar in $\mathrm{WT}$ mice and $\mathrm{GFP} /+{ }^{\mathrm{RFP} /+}$ mice; thus, we combined the data from WT and $\mathrm{GFP} /+{ }^{\mathrm{RFP} /+}$ mice (Fig. $1 D-H$ ). Compared with the contralateral $\mathrm{CP}$, the percentage of $\mathrm{CD} 45^{+} \mathrm{CD} 11 \mathrm{~b}^{+}$cells in the ipsilateral CP was significantly increased (Fig. 1F). Neutrophils $\left(\mathrm{CD} 45^{\text {high }} \mathrm{CD} 11 \mathrm{~b}^{+} \mathrm{Ly}^{+} \mathrm{g}^{+}\right.$; Fig. $\left.1 G\right)$ and inflammatory monocytes (CD $45^{\text {high }}$ $\mathrm{CD}_{1} 1 \mathrm{~b}^{+} \mathrm{Ly}_{6 \mathrm{c}}{ }^{+}$; Fig. 1H) comprised $\sim 1 \%$ of the myeloid cell population in contralateral CP, whereas tMCAO led to a small but significant increase in the percentage of neutrophils (Fig. 1G) and $\mathrm{CD} 45^{\text {high }} \mathrm{CD} 11 \mathrm{~b}^{+} \mathrm{Ly}_{6 \mathrm{c}^{+}}$monocytes (Fig. 1H). These data suggest that, while the lateral CPs within the ventricles are anatomically connected, myeloid cells rapidly mobilize toward the ipsilateral CP following evolving ischemic damage in the neonatal brain.

Consistent with immunofluorescence data (Fig. $1 A-C$ ), flow cytometry showed that percentage of $\mathrm{CD} 45^{+} \mathrm{CD} 11 \mathrm{~b}^{+}$was significantly lower in mice with dysfunctional CX3CR1-CCR2 signaling

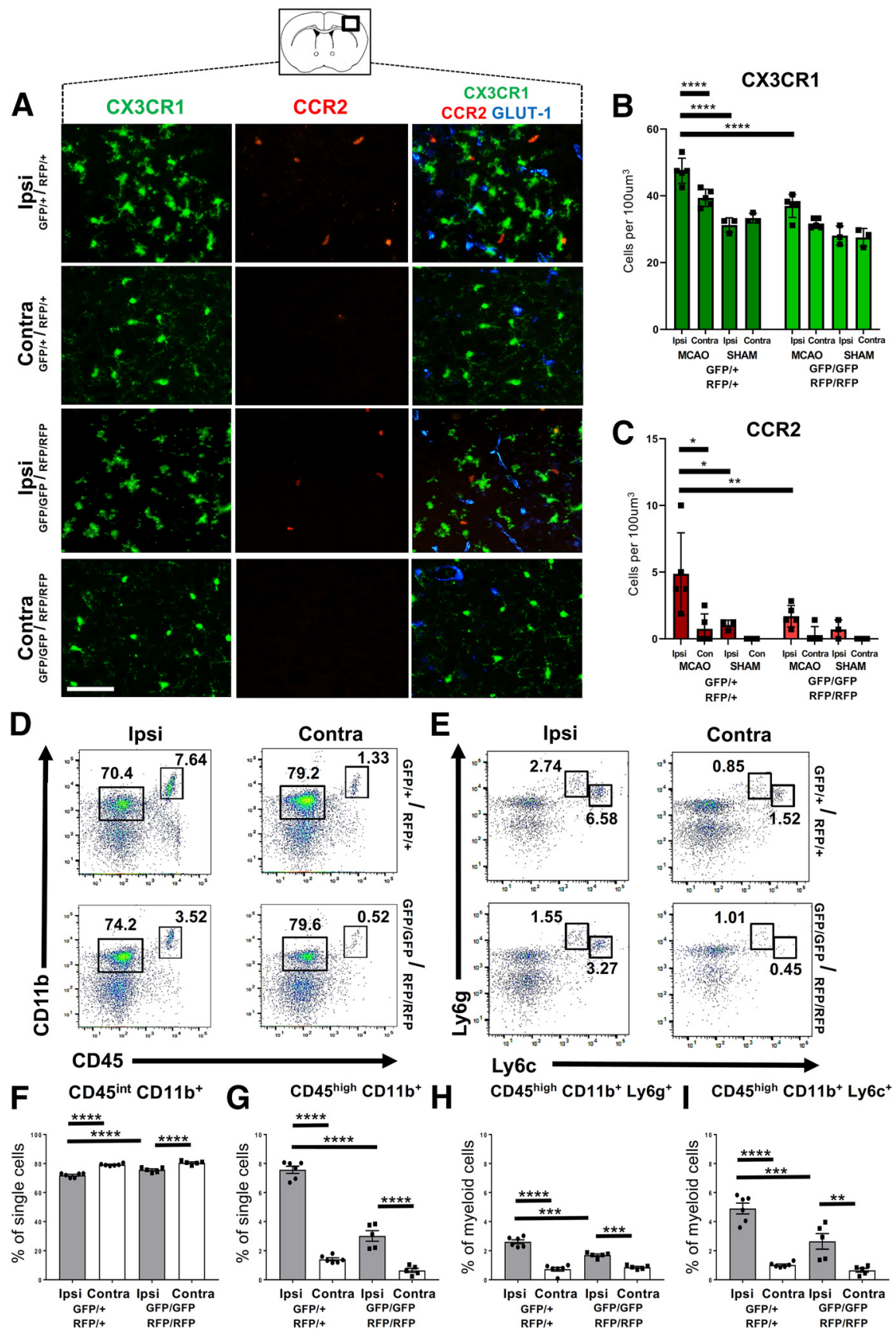

Figure 2. Gradual CX3CR1-CCR2-dependent morphologic transformation of $\mathrm{CX3CR1}{ }^{+}$cells and small but significant accumulation of myeloid cells in the ipsilateral cortex $3 \mathrm{~h}$ after reperfusion. $A$, Representative images of GLUT-1-immunostained sections of $\mathrm{CX}_{3} \mathrm{RR}^{+}{ }^{+}$and $\mathrm{CCR2}^{+}$cells in ipsilateral and contralateral cortex in ${ }^{\text {GFP/+ }} /{ }^{\mathrm{RFP} /+}$ and ${ }^{\text {GFP/GFP }} / \mathrm{RFP} / \mathrm{RFP}$ mice. Images are taken in the same coronal sections shown in Figure 1. Scale bar, $50 \mu \mathrm{m}$. Black box on histologic section represents where images were taken. $B, C$, Quantification of the number of $\mathrm{GFP}^{+}(\boldsymbol{B})$ and $\mathrm{RFP}^{+}(\boldsymbol{C})$ cells in the ipsilateral and contralateral cortex from ${ }^{\mathrm{GFP} /+} \mathrm{p}^{\mathrm{RFP} /+}$ and ${ }^{\text {GPP/GFP } / R F P / R P P}$ mice subjected to TMCAO or sham surgery. D-I, Characterization of myeloid cells from dissociated cortical regions by flow cytometry. $\boldsymbol{D}$, Gating strategy to identify $C D 45^{\text {int }}\left(D 11 b^{+}\right.$and $C D 45^{\text {high }}\left(D 11 b^{+}\right.$cells. $\boldsymbol{E}$, Gating strategy for

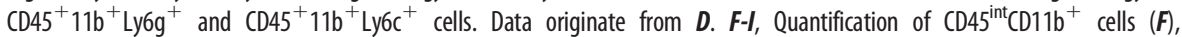

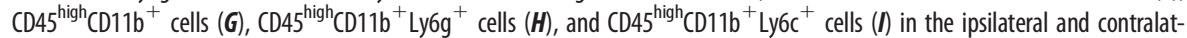
eral cortices. Data are mean \pm SEM. $\boldsymbol{B}, \boldsymbol{C}, \boldsymbol{F}-\boldsymbol{I}^{*}{ }^{*} p<0.05 ;{ }^{* *} p<0.01 ;{ }^{* * *} p<0.001 ;{ }^{* * * *} p<0.0001$; two-way ANOVA with Tukey's Multiple Comparison post hoc test.

compared with mice with functional CX3CR1-CCR2 signaling (Fig. $1 F$ ), whereas the relative changes for $\mathrm{CD} 45^{+} \mathrm{CD} 11 \mathrm{~b}^{+} \mathrm{Ly}_{6 \mathrm{~g}}{ }^{+}$ and $\mathrm{CD}_{4} 5^{+} \mathrm{CD} 11 \mathrm{~b}^{+} \mathrm{Ly}_{6 \mathrm{c}^{+}}$cells were similar in $\mathrm{GFP} / \mathrm{GFP} / \mathrm{RFP} / \mathrm{RFP}$ mice (Fig. $1 G, H$ ). Cumulatively, these data demonstrate unilateral CX3CR1-CCR2-dependent increase in the percentage of $\mathrm{CD} 45^{+} \mathrm{CD} 11 \mathrm{~b}^{+}$myeloid cells in the $\mathrm{CP}$ ipsilateral to the 
A

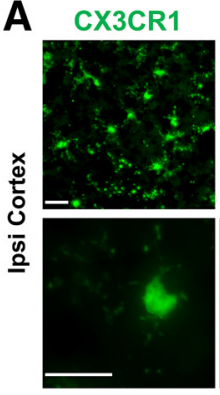

B

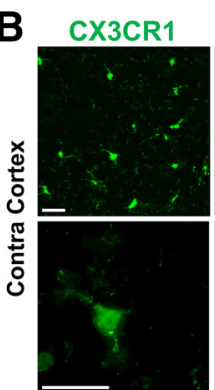

E
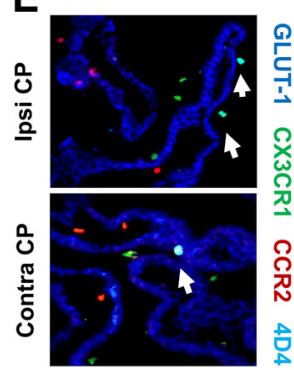

$\mathbf{F}$

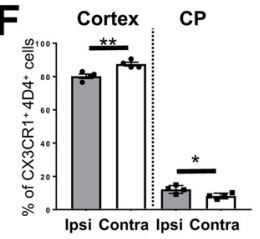

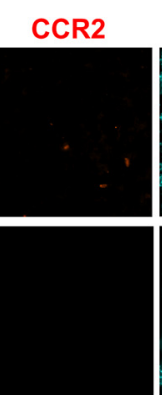
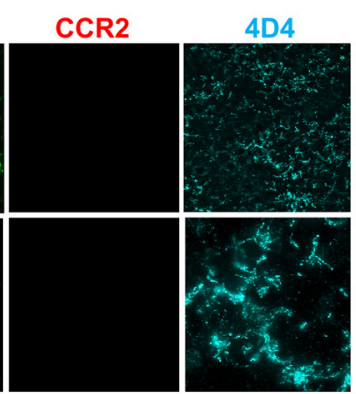

G
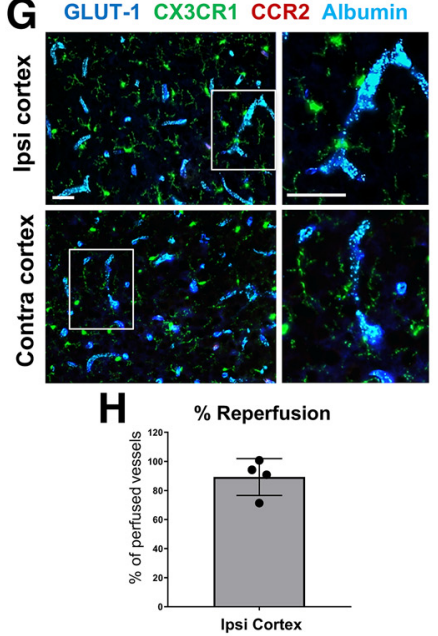

GLUT-1 CX3CR1 CCR2 4D4
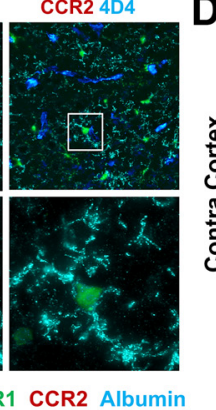

GLUT-1 CX3CR1 GLUT-1 CX3CR1

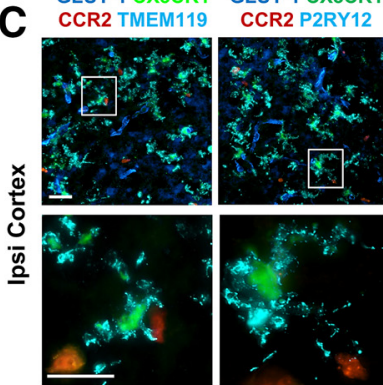

GLUT-1 CX3CR1 GLUT-1 CX3CR1
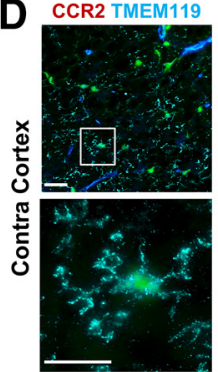

I

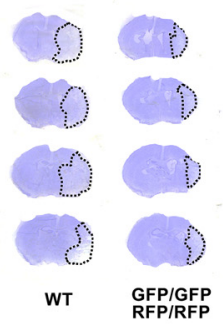

$\mathbf{J}$

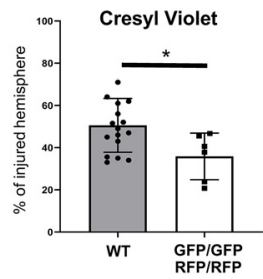

Figure 3. Identification of the origin of $C X 3 \mathrm{CR}^{+}$cells $3 \mathrm{~h}$ after reperfusion and effects of $\mathrm{CX} 3 \mathrm{CR} 1-\mathrm{CCR} 2$ dysfunction on $\mathrm{BBB}$ integrity and subchronic injury. $A, B$, Representative images of $\mathrm{CX3CR} 1^{+}, \mathrm{CCR2}^{+}, 4 \mathrm{D} 4^{+}$, and merged $\mathrm{CX3CR} 1^{+} / \mathrm{CCR2}^{+} / 4 \mathrm{D} 4^{+}$/ GLUT-1 ${ }^{+}$in the ipsilateral $(\boldsymbol{A})$ and contralateral $(\boldsymbol{B})$ cortex in sections adjacent to those shown in Figure 2 . White boxes represent higher-magnification images from areas shown in respective bottom rows. $\boldsymbol{C}, \boldsymbol{D}$, Representative images of ipsilateral $(\boldsymbol{C})$ and contralateral (D) cortical regions immunolabeled with microglia-specific markers TMEM119 and P2RY12. Blue represents GLUT-1 ${ }^{+}$ vasculature. Scale bar, $30 \mu \mathrm{m}$. Note similar branched patterns of $\mathrm{CX} 3 \mathrm{CR} 1^{+}$in $\boldsymbol{A}$ and $\boldsymbol{C .} \boldsymbol{E}, 0$ ccasional $4 \mathrm{D} 4^{+} \mathrm{CX} 3 \mathrm{CR} 1^{+}$colabeled

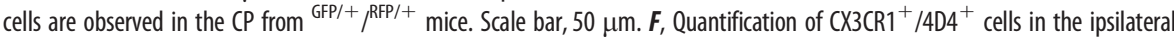
and contralateral cortex and CPs in ${ }^{\mathrm{GFP} /+} / \mathrm{RFP} /+$ mice. $\boldsymbol{G}, \boldsymbol{H}$, Representative images of intravascular appearance of Alexa647-albumin in both ipsilateral and contralateral cortex of ${ }^{\mathrm{GF} /+} /^{R F P /+}$ mice $3 \mathrm{~h}$ after reperfusion. $\mathbf{G}$, Inset, High-magnification images. Scale bar, $30 \mu \mathrm{m}$. $\boldsymbol{H}$, Quantification of percent of GLUT-1 ${ }^{+}$vessels perfused with Alexa647-albumin in ipsilateral cortex in GFP/+ $\rho^{R P P /+}$ mice. $I, J$, Representative images of cresyl violet-stained sections $(I)$ and quantification of injury volume $(J)$ in WT and ${ }^{\text {GFP/GFP } / R F P / R F P}$ mice $72 \mathrm{~h}$ after reperfusion. $\boldsymbol{F}, \boldsymbol{J},{ }^{*} p<0.05 ;{ }^{* *} p<0.01$; Student's $t$ test with Mann-Whitney $U$ post hoc test.

occlusion, including accumulation of both neutrophils and monocytes.

Acute ischemia-reperfusion induces gradual CX3CR1-CCR2dependent morphologic transformation of $\mathrm{CX}_{3} \mathrm{CR}^{+}{ }^{+}$cells and small but significant accumulation of myeloid cells in the ipsilateral cortex

To understand the relationship between accumulation of myeloid cells in the CP and effects in the cortex, we next examined the patterns of microglial activation and transmigration of peripheral myeloid cells into the cortex of the same mice with intact

or disrupted CX3CR1-CCR2 signaling. Quantitative analysis revealed significantly increased number of CX3CR1 ${ }^{+}$ cells in $\mathrm{GFP} /+/ \mathrm{RFP} /+$ mice in ischemicreperfused cortex compared with contralateral cortex or cortex of shamoperated pups (Fig. 2A,B) and signs of morphologic changes in $\mathrm{CX}_{3} \mathrm{CR} 1^{+}$ microglia, which displayed thicker and more retracted processes at this early time point (Fig. 2A). Disrupted CX3CR1-CCR2 signaling significantly reduced the number of $\mathrm{CX} 3 \mathrm{CR} 1^{+}$cells in both the contralateral and ipsilateral cortex (Fig. 2B). A small but significant increase in the number of CCR2 ${ }^{+}$cells (Fig. $2 C$ ) was seen in ipsilateral compared with contralateral cortex and cortex of sham-operated $\mathrm{GFP} /+{ }^{\mathrm{RFP} /+}$ mice (Fig. $2 \mathrm{C}$ ), whereas the number of CCR2 ${ }^{+}$cells was significantly lower ipsilateral to tMCAO of $\mathrm{GFP} / \mathrm{GFP} / \mathrm{RFP} / \mathrm{RFP}$ mice (Fig. 2C).

Flow cytometry showed a significantly decreased percentage of CD $45^{\text {int }}$ $\mathrm{CD}_{11 \mathrm{~b}^{+}}$cells and a parallel increase in percentage of $\mathrm{CD} 45^{\text {high }} \mathrm{CD} 11 \mathrm{~b}^{+}$cells in the ipsilateral cortex, independently demonstrating gradual morphologic transformation of microglia cells in both mouse types (Fig. 2D,F,G). Compared with the contralateral cortex, a small but significant CX3CR1CCR2-dependent increase of $\mathrm{CD} 45^{\text {high }}$

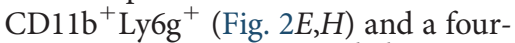
fold increase in $\mathrm{CD} 45^{\text {high }} \mathrm{CD} 11 \mathrm{~b}^{+}$ Ly6c ${ }^{+}$cells (Fig. 2E,I) were observed in the ipsilateral cortex. Accumulation of $\mathrm{CD} 45^{\text {high }} \mathrm{CD} 11 \mathrm{~b}^{+} \mathrm{Ly} 6 \mathrm{c}^{+}$cells in the ipsilateral cortex was significantly lower in ${ }^{\mathrm{GFP} / \mathrm{GFP}} / \mathrm{RFP} / \mathrm{RFP}$ mice.

\section{Identification of the origin of} $\mathrm{CX} 3 \mathrm{CR} 1^{+}$cells in acutely injured neonatal brain with microgliaspecific markers

It has been challenging to distinguish microglia from infiltrating peripheral myeloid cells due to the overlap of surface markers, limitations of fate mapping techniques, and the propensity of the cells to change their antigen expression depending on their activation (Jordao et al., 2019; Li et al., 2019; Van Hove et al., 2019). CX3CR1 expression is high in microglial cells, but surveillance monocytes also exhibit high CX3CR1 expression levels (Shechter et al., 2013). To identify the origin of CX3CR1 ${ }^{+}$cells in the cortex, we used several microglia-specific markers, including 4D4, TMEM119, and P2RY12 (Butovsky et al., 2014; Bennett et al., 2016; Faustino et al., 2019). Figure $3 A-D$ demonstrates that the vast majority of $\mathrm{CX}_{3 \mathrm{CR}} 1^{+}$cells are $4 \mathrm{D} 4^{+}, \mathrm{TMEM}_{119^{+}}$, and $\mathrm{P} 2 \mathrm{RY}_{12}{ }^{+}$, confirming that $\mathrm{CX} 3 \mathrm{CR} 1^{+}$cells are indeed predominantly microglia. A small number of $\mathrm{CX} 3 \mathrm{CR} 1^{+}$cells that were 
negative for microglial markers and were not associated with GLUT-1 ${ }^{+}$vessels likely originate from the CP, perivascular spaces, or meninges. Higher-magnification images of the microglia (Fig. $3 A-D$, bottom panels) show that microglia in the ipsilateral cortex have thicker yet more retracted processes compared with the contralateral cortex. CCR2 ${ }^{+}$cells, in turn, were negative for all three microglial markers, consistent with expectations (Fig. 3A-D)

Interestingly, while the majority of cells in the $\mathrm{CP}$ are $\mathrm{CX} 3 \mathrm{CR} 1^{+} 4 \mathrm{D} 4^{-}$, we also observed a subpopulation of CX3CR $1^{+}$ $4 \mathrm{D} 4^{+}$cells contralateral and an additional small but significant increase in the number of CX3CR $1^{+} 4 \mathrm{D} 4^{+}$cells in the ipsilateral $\mathrm{CP}$ (Fig. $3 E, F)$. None of the CCR2 ${ }^{+}$cells was positive for $4 \mathrm{D} 4$ in either the CP or the cortex (Fig. 3A-E).

\section{$\mathrm{BBB}$ leakage remains low early after reperfusion}

In adult stroke models, the BBB is distorted early after injury and leukocytes migrate and infiltrate injured regions (Iadecola and Anrather 2011), whereas in neonatal stroke we reported the BBB to be considerably less permeable within $24 \mathrm{~h}$ after reperfusion (Fernandez-Lopez et al., 2012). To assess completeness of reperfusion and functional status to the $\mathrm{BBB}$ early after suture removal, we administered Alexa647-albumin intravenously at $2 \mathrm{~h}$ after reperfusion, $1 \mathrm{~h}$ before sacrifice, and examined vessel perfusion and the extent of albumin leakage into the brain parenchyma (representative images shown in Fig. 3G). Consistent with our observations in a neonatal rat tMCAO model (Dzietko et al., 2011), within $3 \mathrm{~h}$ after suture removal, vessels remained sufficiently perfused in the regions that were to become infarcted, as evident from Alexa647-albumin circulation through GLUT-1 ${ }^{+}$ vessels (Fig. 3G,H). Occasional vessels looked swollen, but no albumin leakage was observed outside of GLUT-1 vessels (Fig. $3 G$ ), demonstrating the lack of major disruption of BBB integrity early after reperfusion and suggesting that the BBB is unlikely to be the predominant route of peripheral cells to extravagate.

\section{Disruption of CX3CR1-CCR2 signaling protects neonatal brain from stroke}

To evaluate whether disruption of CX3CR1-CCR2 signaling influences ischemic brain damage, we sacrificed mice $72 \mathrm{~h}$ after tMCAO and evaluated the volume of brain damage in cresyl violet-stained sections. Both mice with functional and disrupted CX3CR1-CCR2 signaling developed injury following tMCAO (Fig. 3I,J). Nonetheless, the volume of injury was significantly smaller in GFP/GFP/RFP/RFP mice compared with WT mice (Fig. $3 H-J)$. These data suggest that reduced myeloid cell infiltration to the $\mathrm{CP}$ in mice deficient of CX3CR1 and CCR2 could contribute to protection from tMCAO-mediated brain damage in neonatal mice.

\section{Ischemia-reperfusion rapidly alters the phenotypes of myeloid cells in the ipsilateral CP and triggers cytokine increase in injured brain cortex}

To further characterize the phenotypes of myeloid cells within the CPs, we examined expression of CD86, a marker of classically activated myeloid cells; CD206, a marker for alternatively activated myeloid cells; and TLR2, a receptor known to contribute to stroke, on $\mathrm{CD}_{4} 5^{+} \mathrm{CD} 11 \mathrm{~b}^{+}$cells isolated from the CPs of WT mice $3 \mathrm{~h}$ after reperfusion. A significantly higher number of $\mathrm{CD}_{4} 5^{+} \mathrm{CD} 11 \mathrm{~b}^{+}$myeloid cells in the ipsilateral CP expressed CD206 (Fig. 4B,E). At the same time, the number of CD86expressing cells was also significantly increased (Fig. 4C,F). We previously demonstrated that TLR2 expression in the CPs is
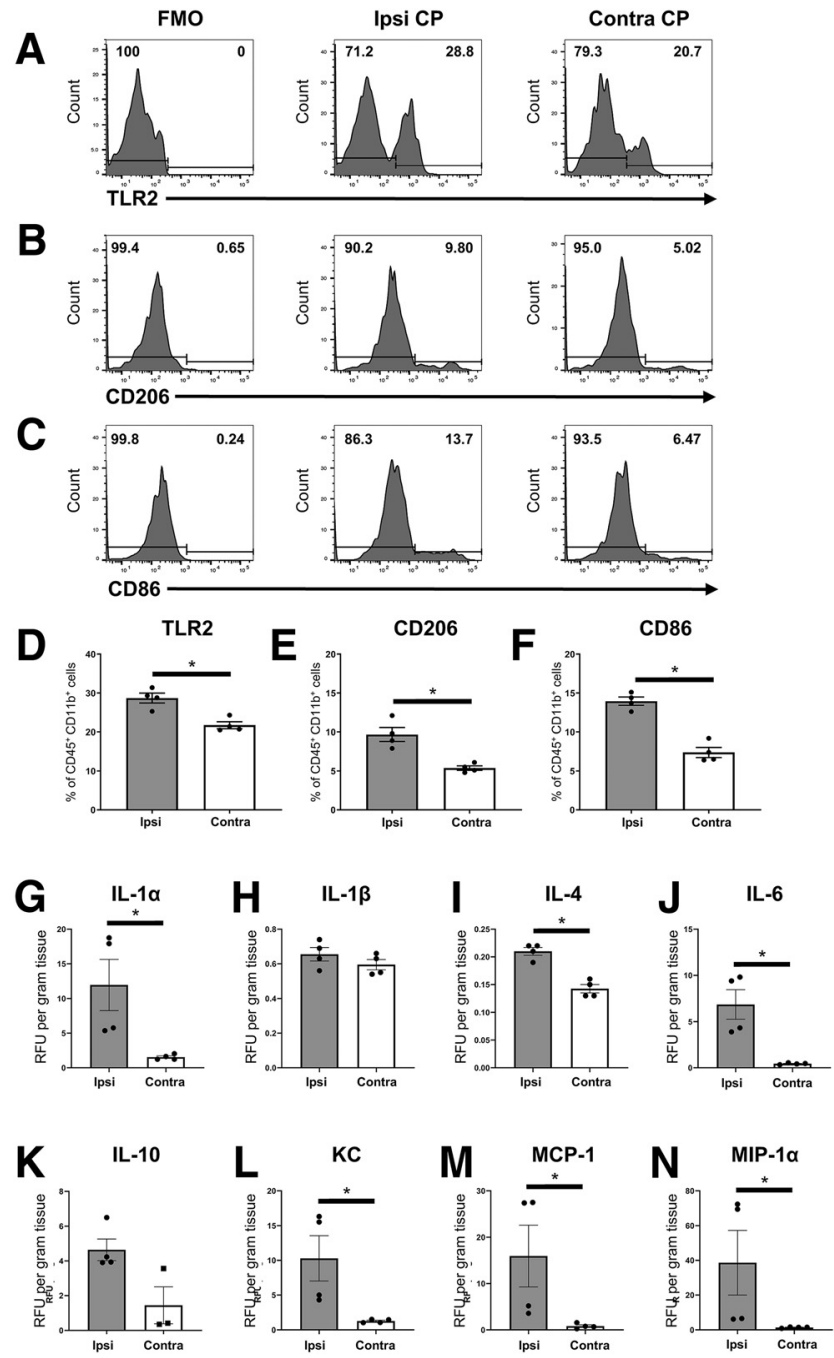

Figure 4. Expression of TLR2, CD206, and CD86 on myeloid cells is increased in the ipsilateral CP $3 \mathrm{~h}$ after reperfusion. $\boldsymbol{A}$ - $\boldsymbol{C}$, Representative flow cytometry histograms for TLR2 (A), CD206 $(\boldsymbol{B})$, and CD86 (C) in Fluorescence Minus One controls (left), ipsilateral CP (middle), and contralateral CP (right) in WT mice. Gate: $\mathrm{CD}^{+} 5^{+} \mathrm{CD} 11 \mathrm{~b}^{+}$cells. D-F, Quantification of data in $\boldsymbol{A}$-C. Compared with contralateral CPs, the number of TLR2 ${ }^{+}(\boldsymbol{D}), \mathrm{CD}_{206^{+}}(\boldsymbol{E})$, and $\mathrm{CD}^{+}(\boldsymbol{F})$ cells is significantly increased in the ipsilateral (P in WT mice. $\mathbf{G}-\boldsymbol{N}$, Multiplex cytokine assay to measure IL-1 $\alpha(\boldsymbol{G}), \mathrm{IL}-1 \beta(\boldsymbol{H}), \mathrm{IL}-4(\boldsymbol{I})$, IL-6 (J), IL-10 (K), KC (L), MCP-1 $(\boldsymbol{M})$, and MIP-1 $\alpha(\boldsymbol{N})$ in ipsilateral and contralateral WT cortex. $\boldsymbol{D}-\boldsymbol{N},{ }^{*} p<0.05$; Student's $t$ test with Mann-Whitney U post hoc test.

high during physiological neonatal development between P8 and P12 and gradually declines by P18 (Lalancette-Hebert et al., 2017). Here we show an increased number of TLR2expressing $\mathrm{CD}_{4} 5^{+} \mathrm{CD} 1 \mathrm{bb}^{+}$cells in the ipsilateral CP (Fig. $4 \mathrm{~A}$, $D$ ). Cumulatively, these data show significant accumulation of both inflammatory and alternatively activated myeloid cells in the CP ipsilateral to tMCAO.

Cytokine multiplex assay revealed a significant increase in numerous inflammatory cytokines and chemokines in the ipsilateral cortex $3 \mathrm{~h}$ after reperfusion, including major neutrophil and monocyte chemoattractant proteins, a neutrophil chemokine $\mathrm{KC}$ that signals via CXCR1/2 and monocyte chemokine MCP-1, cognate chemokine for CCR2 (Fig. 4G-N). Consistent with the presence of an array of myeloid phenotypes, a rapid increase of both inflammatory (IL- $1 \alpha$, IL-6) and anti-inflammatory (IL-4, IL-10) cytokines was observed (Fig. $4 G-N$ ). The levels of IL-1 $\beta$ were not affected (Fig. 4H). Together, these data demonstrate the 


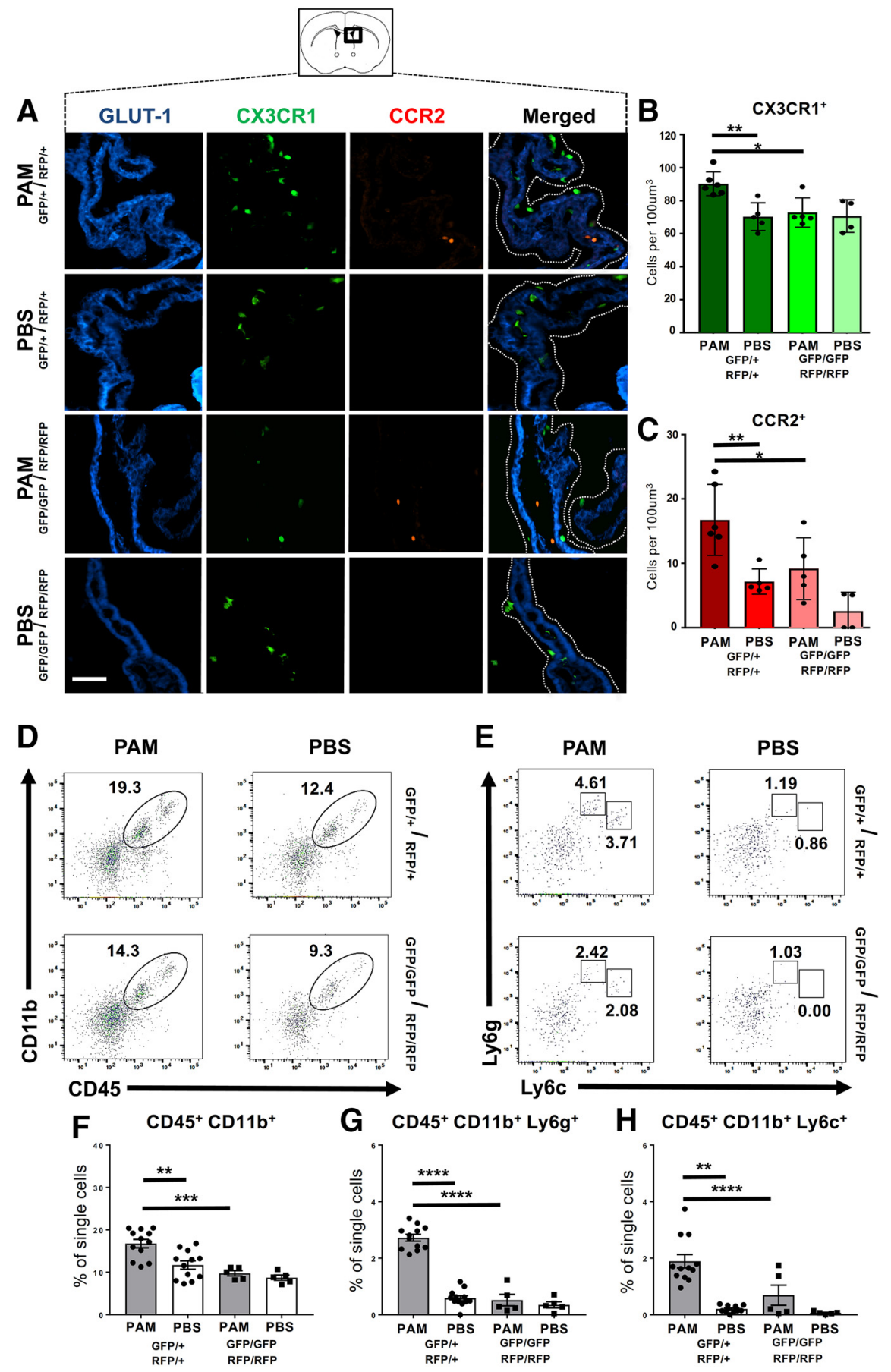

Figure 5. TLR1/2 ligand PAM induces robust CX3CR1-CCR2-dependent accumulation of myeloid cells in the CP within $6 \mathrm{~h}$. $A$, Representative images of $\mathrm{CX}_{3} \mathrm{CR}^{+}$and $\mathrm{CCR}^{+}$cells in GLUT-1-immunostained CPs of PAM- and PBS-treated ${ }^{\mathrm{GFP} /+}{ }^{\text {RFP/+ }}$ and GFP/GFP RFP/RFP mice. Scale bar, $50 \mu \mathrm{m}$. Black box on histologic section represents areas where images were taken. Dashed white lines indicate areas where cells were counted. $\boldsymbol{B}, \boldsymbol{C}$, Quantification of the number of $\mathrm{CX}_{3} \mathrm{CR} 1^{+}(\boldsymbol{B})$ and

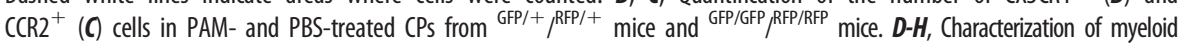
cells from dissociated CPs by flow cytometry. Gating strategy to identify $\mathrm{CD}^{+} 5^{+} \mathrm{CD} 11 \mathrm{~b}^{+}$cells (D) and $\mathrm{CD}^{+} 5^{+} 11 \mathrm{~b}^{+} \mathrm{Ly}_{\mathrm{Gg}}{ }^{+}$and

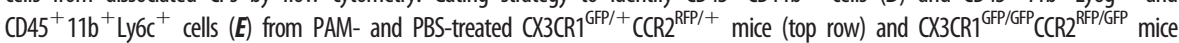
(bottom row). $\boldsymbol{E}$, Data originate from $\mathrm{CD}_{4} 5^{+} \mathrm{CD} 11 \mathrm{~b}^{+}$gate in $\boldsymbol{D}$. $\boldsymbol{F}$-H. Quantification of $\mathrm{CD}^{+} 5^{+} \mathrm{CD} 11 \mathrm{~b}{ }^{+}(\boldsymbol{F}), \mathrm{CD}^{+} 5^{+} \mathrm{CD}_{11 \mathrm{~b}}{ }^{+} \mathrm{Lygg}^{+}$

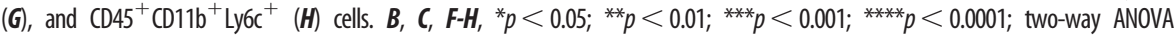
with Tukey's Multiple Comparison post hoc test.

presence of neuroinflammation despite minimal infiltration of immune cells into the cortex early after reperfusion, effects that may in part occur via initiated recruitment of immune cells via the $\mathrm{CP}$
TLR1/2 ligand administration induces rapid CX3CR1-CCR2dependent accumulation of myeloid cells in the $\mathrm{CP}$ and gradual microglial morphologic transformation and monocyte infiltration in the cortex

Considering the complexity of myeloid populations in the CP and TLR2 upregulation in the ipsilateral CP early after reperfusion (Fig. 4), we used a second and simpler neonatal brain injury model (i.e., administration of TLR2 agonist PAM) to examine the TLR2-mediated accumulation and phenotypes of myeloid cells in the CPs (Fig. 5) and in the cortex (Fig. 6). Again, we focused on an early point, 6 $\mathrm{h}$ after injection to compare effects with those induced by $3 \mathrm{~h}$ MCAO followed by $3 \mathrm{~h}$ of reperfusion.

PAM administration significantly increased the number of $\mathrm{GFP}^{+}$(Fig. 5B) and $\mathrm{RFP}^{+}$(Fig. $5 C$ ) cells in the CPs (demarcated by GLUT1; Fig. 5A) in mice with intact CX3CR1-CCR2 signaling, but accumulation of both $\mathrm{GFP}^{+}$ cells and $\mathrm{RFP}^{+}$cells was significantly attenuated in mice with deficient CX3CR1-CCR2 signaling (Fig. 5B,C). The significantly increased $\mathrm{CD} 45^{+}$ $\mathrm{CD}_{11 \mathrm{~b}^{+}}$accumulation in the CP (Fig. $5 D$ ) included $\mathrm{CD} 45^{\text {high }} \mathrm{CD} 11 \mathrm{~b}^{+} \mathrm{Ly} \mathrm{g}^{+}$ neutrophils (Fig. 5G) and $\mathrm{CD} 45^{\text {high }}$

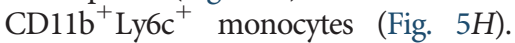
Compared with PBS-treated mice, the percentage of $\mathrm{CD}_{4}{ }^{+} \mathrm{CD} 11 \mathrm{~b}^{+}$cells in the $\mathrm{CP}$ of PAM-treated mice was increased by $\sim 40 \%$ (Fig. $5 F$ ). An overall PAM-induced accumulation of CD $45^{+}$ $\mathrm{CD}_{11 b^{+}}$cells was lower than observed after tMCAO (Fig. 5D,F), while the presence of $\mathrm{GFP}^{+}$and $\mathrm{RFP}^{+}$cells was similar in PBS-treated pups and in contralateral CP following tMCAO (Fig. 5B,C).

Consistent with immunofluorescence data (Fig. 5A-C), following PAM administration, the percentage of $\mathrm{CD} 45^{+}$ $\mathrm{CD}_{11 \mathrm{~b}^{+}}$cells was significantly lower in mice with dysfunctional CX3CR1-CCR2 signaling in both models (Fig. 5F,G), echoing that accumulation of CD $45^{\text {high }}$

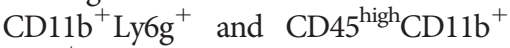
$\mathrm{Ly} \mathrm{c}^{+}$cells was attenuated in mice with dysfunctional CX3CR1-CCR2 signaling (Fig. 5G,H). In the cortex, compared with PBS, PAM significantly increased the number of $\mathrm{CX} 3 \mathrm{CR} 1^{+}$cells (Fig. $6 A$, $B)$ and induced a small but significant increase in the number of $\mathrm{CCR}^{+}$cells (Fig. $6 \mathrm{C}$ ). Disrupted CX3CR1-CCR2 signaling significantly reduced the number of $\mathrm{CX}_{3 \mathrm{CR}}{ }^{+}$and $\mathrm{CCR} 2^{+}$cells regardless of treatment (Fig. $6 B$ ). 
Flow cytometry showed significant PAM-induced increase in $\mathrm{CD} 45^{\text {high }} \mathrm{CD} 11 \mathrm{~b}^{+}$cells in the cortex of $\mathrm{GFP} /+/ \mathrm{RFP} /+$ mice, but not in GFP/GFP/RFP/RFP mice (Fig. 6D-I). PAM also significantly increased infiltration of neutrophils and monocytes in PAM-treated $\mathrm{GFP} /+{ }^{\mathrm{RFP} /+}$ mice (Fig. 6G-I). Together, these data show that PAM/TLR2 activation rapidly enhances myeloid cell trafficking, with magnitude of accumulation in the CPs and in the cortex distinct compared with tMCAO, at least at early time points. PAM produces a larger effect on neutrophil accumulation, whereas tMCAO is preferentially associated with recruitment of inflammatory monocytes.

\section{CX3CR1-CCR2 deficiency attenuates PAM-triggered accumulation of $\mathrm{CXCR}^{+}$ neutrophils}

Considering that in both models neutrophil infiltration into the cortex was modestly yet significantly increased, and that accumulation was attenuated in the cortex of GFP/GFP/RFP/RFP mice after tMCAO

(Fig. 2) and PAM administration (Fig. 6), we explored how CX3CR1CCR2-mediated monocyte signaling affects neutrophil behavior in the PAM model. While neutrophils express several chemokine receptors, CXCR2 is the primary receptor that facilitates their recruitment into inflammatory sites (McColl and Clark-Lewis 1999). In a neonatal rat tMCAO model, concentration of its ligand CINC-1 (KC in mouse) in the blood and ischemic-reperfused regions increased robustly (Denker et al., 2007), but neutrophil infiltration remained low (FernandezLopez et al., 2012).

PAM administration recruited a greater number of $\mathrm{CD} 45^{\text {high }}$ $\mathrm{CD}_{11} \mathrm{~b}^{+}$cells, $\mathrm{CD} 45^{\text {high }} \mathrm{CD} 11 \mathrm{~b}^{+}$ $\mathrm{Ly} \mathrm{g}^{+}$cells, CD $45^{\text {high }} \mathrm{CD} 11 \mathrm{~b}^{+} \mathrm{Ly} \mathrm{g}^{+}$ $\mathrm{CXCR}^{+}$cells, and $\mathrm{CD} 45^{\text {high }}$

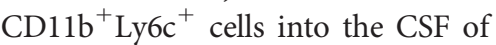
WT mice compared with PBS-treated mice (Fig. $7 B-E$ ). While the percent increase of $\mathrm{CD} 45^{\text {high }} \mathrm{CD} 11 \mathrm{~b}^{+}$and CD $45^{\text {high }} \mathrm{CD} 11 \mathrm{~b}^{+} \mathrm{Ly} \mathrm{g}^{+}$cells in the blood of PAM-treated mice was similarly increased in WT and GFP/GFP/RFP/RFP mice, the percentage of cells expressing CXCR2 was significantly lower in PAM-treated compared with PBStreated GFP/GFP/RFP/RFP mice (Fig. $7 H$ ). Last, the number of $\mathrm{CD} 45^{\text {high }} \mathrm{CD} 11 \mathrm{~b}^{+} \mathrm{Ly} 6 \mathrm{~g}^{+} \mathrm{CXCR} 2^{+}$cells was significantly higher in the CP of PAM-treated WT mice compared with PAM-treated

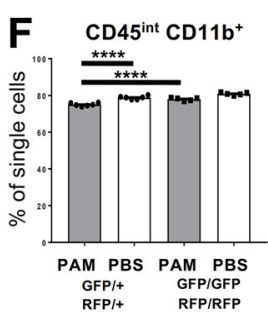

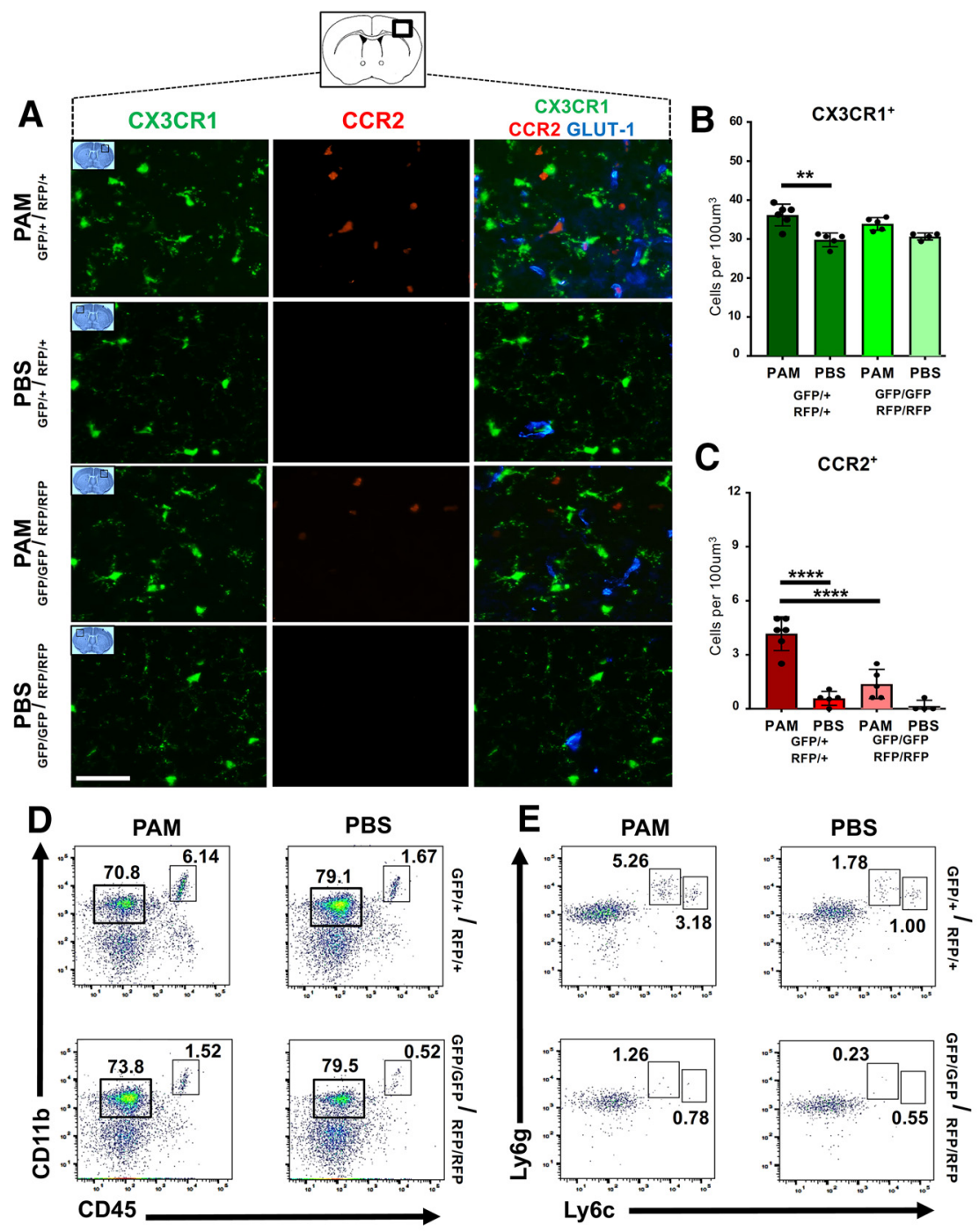
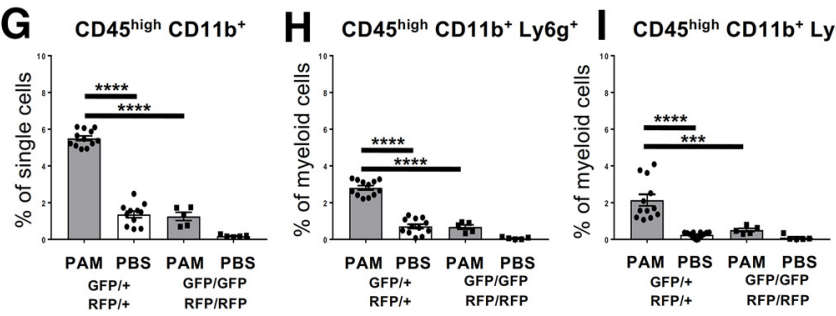

Figure 6. PAM induces gradual CX3CR1-CCR2-dependent microglial activation and small increase in myeloid cell number in the cortex at 6 h. $\boldsymbol{A}$, Representative images of $C X 3 C R 1^{+}$and $C\left(R 22^{+}\right.$cells in the cortex in PAM- or PBS-treated ${ }^{\text {GFP/+ }}$ pFP/+ $^{\text {and }}{ }^{\text {GFP/ }}$

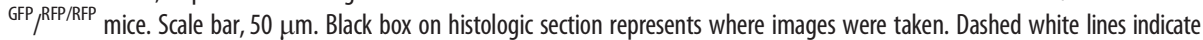
areas where cells were counted. $\boldsymbol{B}, \boldsymbol{C}$, Quantification of the number of $\mathrm{CX3CR1^{+ }}(\boldsymbol{B})$ and $C \mathrm{CR} 2^{+}(\boldsymbol{C})$ cells in the cortex of PAM- and PBS-treated ${ }^{\text {GFP/+ }} /^{\text {RFP/+ }}$ mice and ${ }^{\text {GFP/GFP } / \text { RFP/RFP }}$ mice. D-I, Characterization of microglial cells and myeloid cells by flow cytometry in

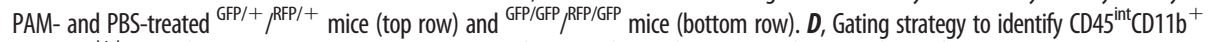
and $\mathrm{CD} 45^{\text {high }} \mathrm{CD} 11 \mathrm{~b}^{+}$cells. $\boldsymbol{E}$, Gating strategy for $\mathrm{CD} 45^{+} \mathrm{CD} 11 \mathrm{~b}^{+} \mathrm{Ly}_{6 \mathrm{~g}}{ }^{+}$and $\mathrm{CD} 45^{+} \mathrm{CD} 11 \mathrm{~b}^{+} \mathrm{Ly}_{6 \mathrm{C}^{+}}$cells. $\boldsymbol{F}, \boldsymbol{G}$, Quantification

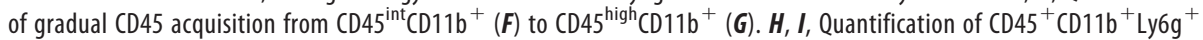

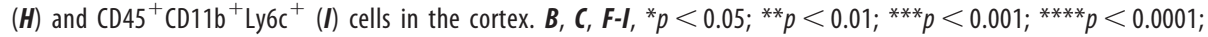
two-way ANOVA with Tukey's Multiple Comparison post hoc test.

GFP/GFP/RFP/RFP mice (Fig. 7J). Together, these data suggest that, while neutrophil infiltration into the brain is minor following acute TLR2 stimulation, neutrophils can mediate neuroinflammation from the blood, CP, and CSF in part by CXCR1-CCR2 signaling. Disrupted CXCR1-CCR2 function, which attenuates CXCR2 expression on peripheral cells, limits neutrophil infiltration, potentially contributing to neuroprotection. 


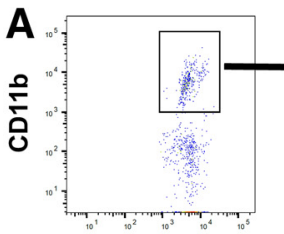

CD45
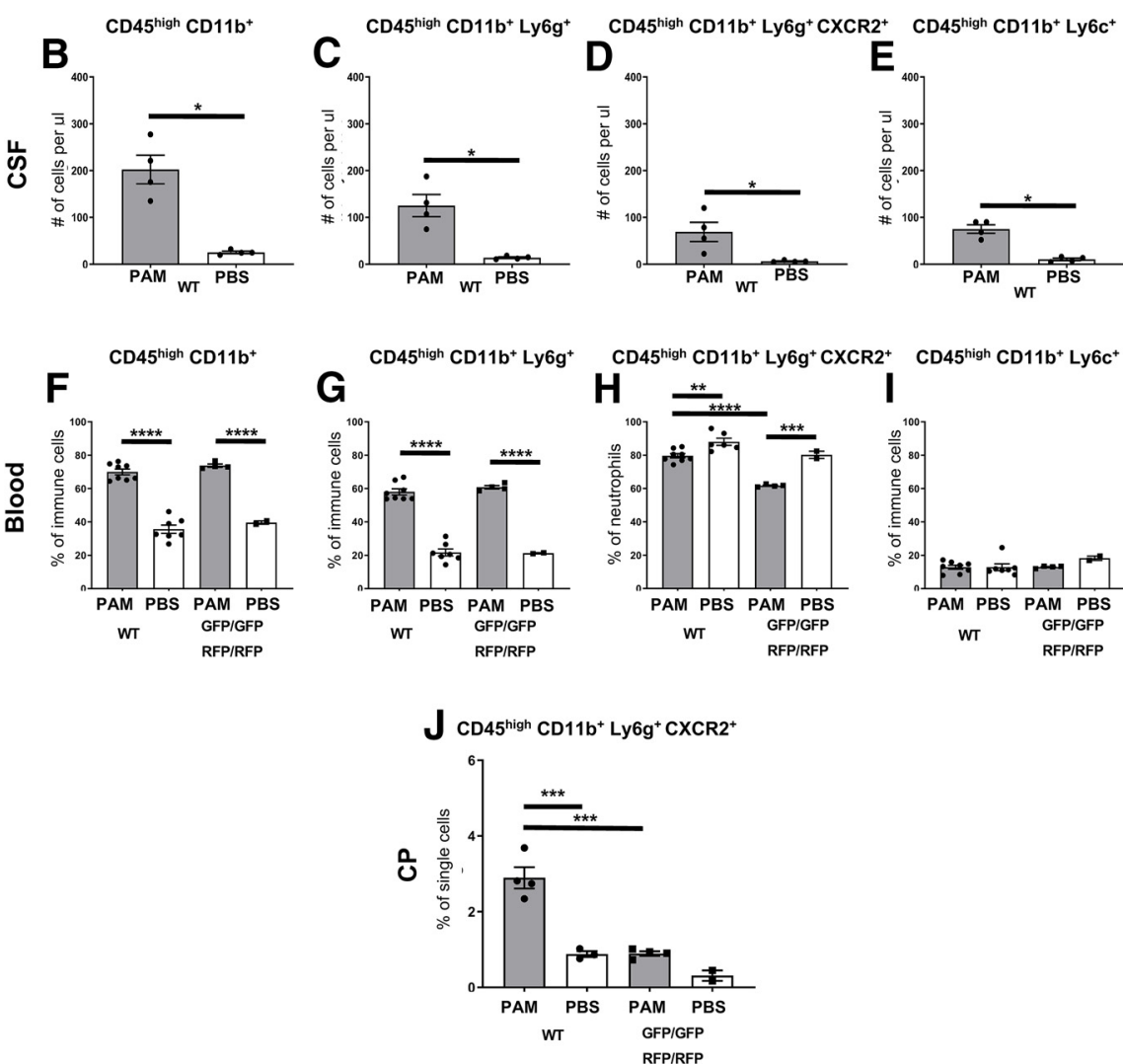

Figure 7. Disruption of CX3CR1-CCR2 signaling attenuates PAM-induced accumulation of CXCR2 expression on neutrophils in the blood and the CP within 6 h. A, Gating strategy in CSF and blood samples. B-E, Quantification for CD45 high ${ }^{\text {he } 11 b^{+}}$

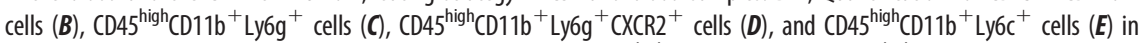

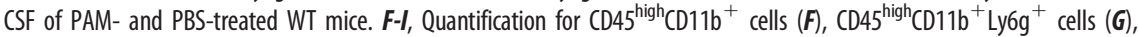
$\mathrm{CD}^{\text {high }}{ }^{\mathrm{h}} \mathrm{CD} 11 \mathrm{~b}^{+} \mathrm{Ly}_{6 \mathrm{~g}}{ }^{+} \mathrm{CXCR2}{ }^{+}$cells $(\boldsymbol{H})$, and $\mathrm{CD} 45^{\text {high }} \mathrm{CD} 11 \mathrm{~b}^{+} \mathrm{Ly}^{+} \mathrm{c}^{+}$cells $(\boldsymbol{I})$ in blood of PAM- and PBS-treated WT and ${ }^{\mathrm{GPP} /}$ GFP /RFP/RFP mice. J, Quantification of CD45 high $\mathrm{CD} 1 \mathrm{~b}^{+} \mathrm{Ly}^{+} \mathrm{g}^{+} \mathrm{CXCR2}{ }^{+}$cells in the CP of PAM- and PBS-treated WT and ${ }^{\text {GFP/ }}$ GFP /RFP/RFP mice. ${ }^{*} p<0.05 ;{ }^{* *} p<0.01 ;{ }^{* * *} p<0.001 ;{ }^{* * *} p<0.0001$; Student's $t$ test with Mann-Whitney U post hoc test $(\boldsymbol{B}-\boldsymbol{E})$ and two-way ANOVA with Tukey's Multiple Comparison post hoc test $(\boldsymbol{F}-\boldsymbol{J})$.

PAM and tMCAO trigger trafficking of distinct subpopulations of pro- and anti-inflammatory leukocytes in the $\mathrm{CP}$ and cortex

Based on our findings of the presence of both toxic and beneficial myeloid phenotypes early after tMCAO, we asked whether the cytokine-based phenotypic signature of myeloid cells within the $\mathrm{CP}$ is distinct in the PAM and tMCAO models. To that end, we compared myeloid cell phenotypes from the CP $6 \mathrm{~h}$ after PAM/ $\mathrm{PBS}$ administration and at $3 \mathrm{~h}$ after reperfusion. PAM promoted accumulation of $\mathrm{CD} 45^{+} \mathrm{CD} 11 \mathrm{~b}^{+} \mathrm{CD} 206^{+} \mathrm{IL}-10^{+}$cells in the CPs compared with both PBS-treated mice and tMCAO mice (Fig. $8 A, C, D)$. PAM also triggered significant accumulation of CD $45^{+}$ $\mathrm{CD} 11 \mathrm{~b}^{+} \mathrm{CD} 86^{+} \mathrm{IL}-1 \beta^{+}$cells in the $\mathrm{CP}$ compared with PBS, but the magnitude of accumulation was lower than in the CP ipsilateral to the occlusion (Fig. $8 B, E, F$ ). These data suggest that, compared with PAM, tMCAO induces a response skewed toward more toxic phenotypes.

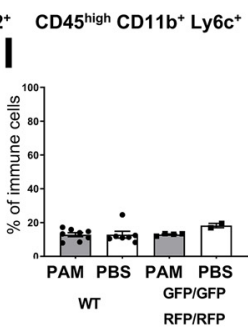

We then asked whether the dynamics of myeloid cell recruitment to the $\mathrm{CP}$ and cortex differs between tMCAO and PAM models. Following PAM treatment for 16 $\mathrm{h}$, the number of $\mathrm{CX} 3 \mathrm{CR} 1^{+}$cells (Fig. $9 A)$ was similar to that at $6 \mathrm{~h}$ in the $\mathrm{CP}$ and cortex (Figs. 5, 6), whereas the number of CCR2 ${ }^{+}$cells was further increased (Fig. 9B) compared with the earlier time point (Figs. 5, 6). Compared with $3 \mathrm{~h}$ after reperfusion (Fig. 1), at $13 \mathrm{~h}$, the number of CX3CR $1^{+}$cells was decreased in both ipsilateral and contralateral CP (Fig. 9C), whereas in the cortex, the number of CX3CR $1^{+}$cells increased. A significantly increased number of $\mathrm{CCR} 2^{+}$cells was observed in the ipsilateral compared with the contralateral cortex (Fig. 9D) at $13 \mathrm{~h}$ reperfusion and the ipsilateral cortex $3 \mathrm{~h}$ after reperfusion as well (Fig. 2). Following tMCAO, there is also an increase in myeloid cells in the CP at $3 \mathrm{~h}$ after reperfusion but a decrease at $13 \mathrm{~h}$ in the $\mathrm{CP}$ and increase in the ipsilateral cortex, suggesting that myeloid cells from the $\mathrm{CP}$ could be entering the ischemic hemisphere following tMCAO during the $3 \mathrm{~h}$ reperfusion to $13 \mathrm{~h}$ reperfusion time window. Flow cytometry in WT mice further elaborated that most myeloid cells are retained in the CP at $16 \mathrm{~h}$ after PAM administration compared with PBS, whereas there is significantly increased influx of myeloid cells to the ipsilateral cortex at $13 \mathrm{~h}$ reperfusion following tMCAO, demonstrating contextdependent early myeloid cell trafficking via the $\mathrm{CP}$.

\section{Discussion}

We report, for the first time, that neonatal stroke triggers robust accumulation of heterogeneous myeloid cell subpopulations in the CP ipsilateral to the occlusion. This includes inflammatory monocytes, beneficial monocytes, and neutrophils, which exert rapid marked neuroinflammatory responses. The accumulation of peripheral immune cells in the ipsilateral cortex remains limited and is not associated with extravascular albumin leakage. We then show that the overall extent and the patterns of leukocytes accumulated in the $\mathrm{CP}$, microglial activation in the brain parenchyma, and injury severity depend on CX3CR1CCR2 signaling, as evident from attenuated responses in mice with dysfunctional CX3CR1 and CCR2 receptors. The effects are not limited to attenuation of monocyte trafficking/signaling but include reduced neutrophil signaling as well. Comparisons of myeloid phenotypes between tMCAO and direct TLR2 stimulation revealed distinct spatiotemporal profiles in the $\mathrm{CP}$ within the proinflammatory versus anti-inflammatory continuum.

The CP has been identified as a gate for immune cell entry to the parenchyma during health and disease as well as for modulating cytokine composition in the CSF (Kunis et al., 2013; 
Schwartz and Baruch 2014). Moreover, in adults, chemokines released from the $\mathrm{CP}$ epithelium can facilitate $\mathrm{CP}$ myeloid cell transmigration into the brain parenchyma (SzmydyngerChodobska et al., 2009). Single-cell RNA sequencing revealed a unique $\mathrm{CP}$-specific transcriptional profile, distinct from microglia or border-associated macrophages, thus pointing to potential novel targets for modulating $\mathrm{CP}$ regulation of immune cell traffic (Van Hove et al., 2019).

While similar immunomodulatory mechanisms are involved in neonatal and adult stroke, it has become clear that maturation-specific "signature" patterns of leukocyte infiltration and microglial activation in neonates exist (Hagberg et al., 2015; Mallard et al., 2018). Following ischemia, dying CNS cells release DAMPs to activate microglia as well as recruit peripheral myeloid cells and produce proinflammatory cytokines (Kono and Rock 2008; Planas et al., 2012; Shichita et al., 2017). At the same time, infiltrating myeloid cells can express anti-inflammatoryrelated surface receptors, such as triggering receptors expressed on myeloid cells (TREM2) and CD206.

These cells can release beneficial cytokines, such as IL-4, IL-10, and TGF $\beta$ (Hu et al., 2013; Matsumoto et al., 2015; Xia et al., 2015; Wu et al., 2017).

In our study in neonatal mice, flow cytometry demonstrated rapid unilateral increase of a heterogeneous pool of myeloid cells in the $\mathrm{CP}$ ipsilateral to the occlusion, including inflammatory IL$1 \beta$-producing cells and anti-inflammatory IL-10-producing cells. Ischemia-reperfusion triggered rapid neuroinflammatory responses manifested by increased levels of cytokines and monocytes and neutrophil chemoattactants (KC and MCP-1, respectively) in regions of evolving injury, yet only few leukocytes entered ischemic-reperfused cortex. As we show in the PAM model, leukocytes rapidly accumulate in the CSF and can signal from the CP, CSF, and peripheral blood. Thus, inflammation is in part the consequence of leukocyte accumulation in the $\mathrm{CP}$ at this early reperfusion time when neuronal death is still sparse but signs of microglial morphologic transformation are apparent with multiple cell types (microglia, CP macrophages, and incoming peripheral myeloid cells), contributing to cytokine and chemokine production.

The use of bone marrow chimeric mice would have been the preferred strategy to establish the relative role of peripheral and local cells in injury, but this strategy is not feasible in neonates due to lack of time for immune reconstitution. Therefore, we used cell type-specific markers to distinguish microglia from infiltrating monocytes. Immunophenotyping of $\mathrm{CX} 3 \mathrm{CR} 1^{\mathrm{GFP}+}$ cells in the $\mathrm{CP}$ and ischemic-reperfused cortex with microgliaspecific markers 4D4, TMEM119, and P2RY12, together with demarcation of CCR2 $2^{\mathrm{RFP}+}$ monocytes, showed that most of $\mathrm{CX}_{3} \mathrm{CR}^{+}{ }^{+}$cells in the $\mathrm{CP}$ were negative for multiple microgliaspecific markers, thus representing phenotypic array of CX3CR1 $1^{\text {high }}$ and $\mathrm{CX} 3 \mathrm{CR} 1^{\text {low }}$ monocytes. Moreover, the number of local CX3CR $1^{+} 4 \mathrm{D} 4^{+}$macrophages increased in the ipsilateral CP, likely due to proliferating $\mathrm{CP}$ macrophages or macrophages that mobilized from either the contralateral $\mathrm{CP}$ or the brain parenchyma following injury. In the parenchyma, the vast majority of $\mathrm{CX}_{3} \mathrm{CR} 1^{+}$cells were microglia and the number of CCR2 ${ }^{+}$ monocytes recruited to the ischemic-reperfused cortex was small, likely contributing to well-preserved neurovascular integrity.

Dysfunction of CX3CR1 and CCR2 led to neuroprotection during subchronic phase, suggesting the pathogenic role of signaling via these receptors. Protection is associated with significant attenuation of early monocyte trafficking via the $\mathrm{CP}$ in mice lacking CX3CR1 and CCR2 signaling. Our data show that this effect could be influenced by attenuation of monocytes and, potentially, neutrophils. While we report rapid recruitment of these cells to the CP, inhibiting CX3CR1 and CCR2 at different time points after MCAO pharmacologically can give us clarity on potential therapeutic windows.

Given the complexity of stroke pathophysiology, our findings that TLR2 activation contributes to neonatal stroke (LalancetteHebert et al., 2017) and that TLR2 activation is a major trigger for leukocyte trafficking via the $\mathrm{CP}$ in neonates (Mottahedin et al., 2017, 2019), we compared the myeloid phenotypes in the CP following stroke and TLR2 activation in neonates. TLR2 effects on ischemic injury are context-dependent and differ between adult and neonatal stroke, as cells of the monocyte lineage exert TLR2-dependent effects in both the mature and immature brain (Lalancette-Hebert et al., 2009, 2017; Bohacek et al., 2012). Excessive activation of TLR2 impairs gray and white matter development in neonates (Du et al., 2011), and TLR2 deficiency 

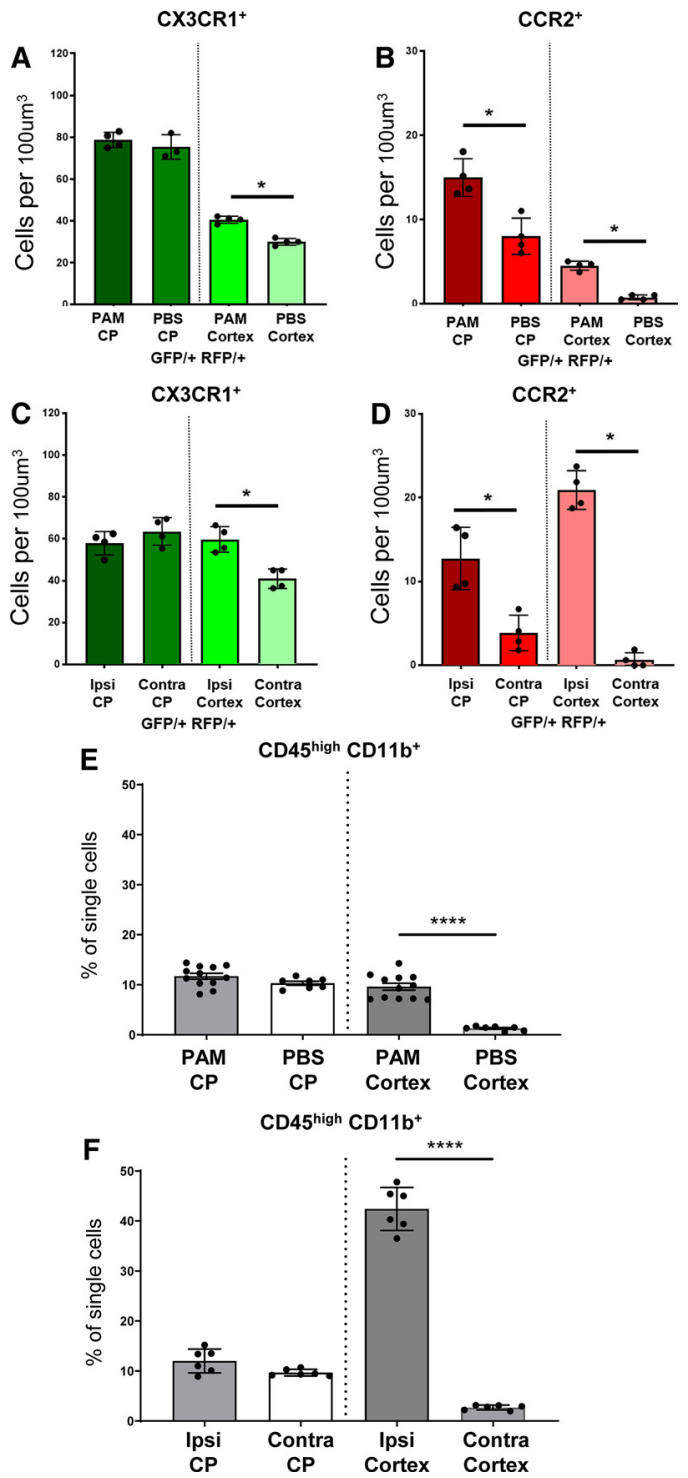

Figure 9. $\quad$ TMCAO and PAM trigger distinct patterns of myeloid cells in the $C P$ and cortex at 16 h. $A, B$, Quantification of the number of $\mathrm{CX}_{3} \mathrm{CR} 1^{+}(\boldsymbol{A})$ and $C \mathrm{CR} 2^{+}(\boldsymbol{B})$ cells in the CPs and the cortex $16 \mathrm{~h}$ after PAM/PBS treatment of ${ }^{\mathrm{GFP} /+} \beta^{\mathrm{RFP} /+}$ mice. $C, \boldsymbol{D}$, In the cortex, calculation is based on the number of cells/tissue volume. Quantification of the number of $\mathrm{CX3CR}^{+}(\mathbf{C})$ and $C \mathrm{CR2}{ }^{+}(\boldsymbol{D})$ cells in ipsilateral and contralateral region $13 \mathrm{~h}$ after tMCAO in GFP/+ $/^{\mathrm{RFP} /+}$ mice. In the CPs, calculation is based on the number of cells $/ 100 \mu \mathrm{m}^{3} / \mathrm{GLUT}-1$ volume. Quantification of $C D 45^{\text {high }} \mathrm{CD} 11 \mathrm{~b}^{+}$cells $16 \mathrm{~h}$ after PAM or PBS in the CP and cortex $(\boldsymbol{E})$ and at $13 \mathrm{~h}$ reperfusion following tMCAO in the ipsilateral and contralateral CPs and cortices of WT mice $(\boldsymbol{F})$. Data are mean \pm SEM. $\boldsymbol{A}-\boldsymbol{D},{ }^{*} p<0.05$; ${ }^{* * *} p<0.0001$; Student's $t$ test with Mann-Whitney $U$ post hoc test.

protects from hypoxia-ischemia (Stridh et al., 2011). Contrastingly, TLR2 stimulation in neonatal mice following sepsis is beneficial by inducing IL-10 production to quell effects of proinflammatory neutrophils (Andrade et al., 2013). TLR2 stimulation also exerts preconditioning effect in neonates ( $\mathrm{Lu}$ et al., 2011; Vexler et al., 2018).

Although accumulation of myeloid cells in the CP following PAM was robust, the myeloid phenotypes accumulated in the $\mathrm{CP}$ were distinct compared with those after tMCAO, including marked impact on neutrophils and a skewed monocyte phenotype toward anti-inflammatory $\left(\mathrm{CD} 45^{+} \mathrm{CD} 11 \mathrm{~b}^{+} \mathrm{CD} 206^{+} \mathrm{IL}\right.$ $10^{+}$). As injury progresses, the leukocyte dynamics continues to differ between direct TLR2 stimulation and tMCAO.
Immunofluorescence and flow cytometry consistently showed that the number of myeloid cells remains stagnant in the $\mathrm{CP}$ $16 \mathrm{~h}$ after PAM injection, whereas there is a noticeable reduction in the presence of myeloid cells in the $\mathrm{CP}$ at $13 \mathrm{~h}$ reperfusion compared with $3 \mathrm{~h}$ reperfusion. In the cortex, the number of $\mathrm{CX} 3 \mathrm{CR} 1^{+}$cells in the ischemic-reperfused regions increases with time, suggesting that they may have migrated from the $\mathrm{CP}$ into the injured parenchyma during that time window or there was enhanced microglial proliferation at that time point. The number of $\mathrm{CCR}^{+}$cells was also much greater in the cortex at the later time point following tMCAO relative to PAM. Assessing the timing of how myeloid cells from different regions enter the injured parenchyma is of future interest and can provide novel insights about ischemic brain pathology. While our data are in agreement with recently published data that TLR2 mediates transmigration of neutrophils and monocytes to the neonatal brain via the $\mathrm{CP}$ (Mottahedin et al., 2019), the effects after tMCAO in neonates do not mirror effects exerted by direct TLR2 stimulation, suggesting that MCAO has both TLR2-dependent and -independent effects.

The data on attenuated neutrophil recruitment to the $\mathrm{CP}$ in pups with dysfunctional CCR2 and CX3CR1 receptors in both models shed light on relationships between monocyte and neutrophil signaling. In WT mice, we show robust neutrophil accumulation not only in the CP but in the CSF as well, yet only minimal infiltration in injured brain regions. In adult, an array of studies by the others have demonstrated that neutrophil behavior is both injury context- and injury severity-dependent (Enzmann et al., 2018), and that stepwise margination and infiltration largely depend on the status of endothelium activation. Links between neutrophil signaling and CCR2-dependent monocyte trafficking exist under various pathophysiological conditions (Souto et al., 2011), including bidirectional signals to each other to influence both activity and migration (Prame Kumar et al., 2018; Lazzaretto and Fadeel, 2019). We discovered that, while PAM administration similarly increases the number of $\mathrm{CD} 45^{\text {high }} \mathrm{CD} 11 \mathrm{~b}^{+}$and $\mathrm{CD} 45^{\text {high }} \mathrm{CD} 11 \mathrm{~b}^{+} \mathrm{Ly} \mathrm{g}^{+}$cells in the blood in mice with functional and dysfunctional CX3CR1-CCR2 signaling, the percent of cells expressing CXCR2 is significantly lower in PAM-treated pups, reducing CXCR2-mediated neutrophil responses to elevated levels of its ligand. While the low rate of neutrophil infiltration after tMCAO is not surprising given our previous observation in a neonatal rat stroke model of low neutrophil infiltration into ischemic-reperfused brain (FernandezLopez et al., 2012) despite elevated brain levels of neutrophil chemoattractant (Denker et al., 2007), this study identifies diminished CXCR2 expression as a contributing factor to reduced neutrophil trafficking into the injured brain.

In conclusion, we have identified the $\mathrm{CP}$ as an important route for early myeloid cell trafficking following neonatal ischemia-reperfusion. These cells include both beneficial and injurious phenotypes with CX3CR1-CCR2 signaling critically influencing their accumulation and injury. These findings suggest that modulating the CP myeloid cell pool could be a potential therapeutic strategy for controlling neonatal strokerelated neuroinflammation. Identifying the chemotactic signals after tMCAO that recruit specific myeloid cell phenotypes to the injured brain from the CP could be key. Furthermore, targeting $\mathrm{CP}$ myeloid cells may provide a unique therapeutic avenue for treating ischemic brain damage, particularly in neonates. 


\section{References}

Aghaeepour N, Finak G, FlowCAP Consortium, Dream Consortium, Hoos H, Mosmann TR, Brinkman R, Gottardo R, Scheuermann RH, et al. (2013) Critical assessment of automated flow cytometry data analysis techniques. Nat Methods 10:228-238.

Andrade EB, Alves J, Madureira P, Oliveira L, Ribeiro A, Cordeiro-da-Silva A, Correia-Neves M, Trieu-Cuot P, Ferreira P (2013) TLR2-induced IL10 production impairs neutrophil recruitment to infected tissues during neonatal bacterial sepsis. J Immunol 191:4759-4768.

Baruch K, Schwartz M (2013) CNS-specific T cells shape brain function via the choroid plexus. Brain Behav Immun 34:11-16.

Bennett ML, Bennett FC, Liddelow SA, Ajami B, Zamanian JL, Fernhoff NB, Mulinyawe SB, Bohlen CJ, Adil A, Tucker A, Weissman IL, Chang EF, Li G, Grant GA, Hayden Gephart MG, Barres BA (2016) New tools for studying microglia in the mouse and human CNS. Proc Natl Acad Sci USA 113:E1738-E1746.

Bohacek I, Cordeau P, Lalancette-Hebert M, Gorup D, Weng YC, Gajovic S, Kriz J (2012) Toll-like receptor 2 deficiency leads to delayed exacerbation of ischemic injury. J Neuroinflammation 9:191.

Butovsky O, Jedrychowski MP, Moore CS, Cialic R, Lanser AJ, Gabriely G, Koeglsperger T, Dake B, Wu PM, Doykan CE, Fanek Z, Liu L, Chen Z, Rothstein JD, Ransohoff RM, Gygi SP, Antel JP, Weiner HL (2014) Identification of a unique TGF-beta-dependent molecular and functional signature in microglia. Nat Neurosci 17:131-143.

Chip S, Fernandez-Lopez D, Faustino J, Li F, Derugin N, Vexler ZS (2017) Genetic deletion of galectin-3 enhances neuroinflammation, affects microglial activation and contributes to sub-chronic injury in experimental neonatal focal stroke. Brain Behav Immun 60:270-281.

Cserép C, Pósfai B, Lénárt N, Fekete R, László ZI, Lele Z, Orsolits B, Molnár G, Heindl S, Schwarcz AD, Ujvári K, Környei Z, Tóth K, Szabadits E, Sperlágh B, Baranyi M, Csiba L, Hortobágyi T, Maglóczky Z, Martinecz $\mathrm{B}$, et al. (2020) Microglia monitor and protect neuronal function through specialized somatic purinergic junctions. Science 367:528-537.

Denker S, Ji S, Lee SY, Dingman A, Derugin N, Wendland M, Vexler ZS (2007) Macrophages are comprised of resident brain microglia not infiltrating peripheral monocytes acutely after neonatal stroke. J Neurochem 100:893-904.

Du X, Fleiss B, Li H, D’Angelo B, Sun Y, Zhu C, Hagberg H, Levy O, Mallard C, Wang X (2011) Systemic stimulation of TLR2 impairs neonatal mouse brain development. PLoS One 6:e19583.

Dzietko M, Faustino J, Derugin N, Wendland MF, Ferriero DM, Vexler ZS (2011) MRI as a translational tool for the study of neonatal stroke. J Child Neurol 26:1145-1153.

Ek CJ, Wong A, Liddelow SA, Johansson PA, Dziegielewska KM, Saunders NR (2010) Efflux mechanisms at the developing brain barriers: ABCtransporters in the fetal and postnatal rat. Toxicol Lett 197:51-59.

Engelhardt B, Sorokin L (2009) The blood-brain and the blood-cerebrospinal fluid barriers: function and dysfunction. Semin Immunopathol 31:497511.

Enzmann G, Kargaran S, Engelhardt B (2018) Ischemia-reperfusion injury in stroke: impact of the brain immune privilege on neutrophil function. Ther Adv Neurol Discord 11:1756286418794184.

Faustino J, Chip S, Derugin N, Jullienne A, Hamer M, Haddad E, Butovsky O, Obenaus A, Vexler ZS (2019) CX3CR1-CCR2-dependent monocytemicroglial signaling modulates neurovascular leakage and acute injury in a mouse model of childhood stroke. J Cereb Blood Flow Metab 39:19191935.

Fernandez-Lopez D, Faustino J, Daneman R, Zhou L, Lee SY, Derugin N, Wendland MF, Vexler ZS (2012) Blood-brain barrier permeability is increased after acute adult stroke but not neonatal stroke in the rat. J Neurosci 32:9588-9600.

Fernandez-Lopez D, Faustino J, Klibanov AL, Derugin N, Blanchard E, Simon F, Leib SL, Vexler ZS (2016) Microglial cells prevent hemorrhage in neonatal focal arterial stroke. J Neurosci 36:2881-2893.

Fernandez-Lopez D, Natarajan N, Ashwal S, Vexler ZS (2014) Mechanisms of perinatal arterial ischemic stroke. J Cereb Blood Flow Metab 34:921932.

Ferriero DM, Fullerton TJ, Bernard L, Billinghurst SR, Daniels MR, DeBaun G, deVeber RN, Ichord LC, Jordan P, Massicotte J, Meldau ES, Roach ER, Smith C (2019) Management of stroke in neonates and children: a scientific statement from the American Heart Association/American Stroke Association. Stroke 50:e51-e96.
Fumagalli S, Perego C, Pischiutta F, Zanier ER, De Simoni MG (2015) The ischemic environment drives microglia and macrophage function. Front Neurol 6:81.

Garcia-Bonilla L, Faraco G, Moore J, Murphy M, Racchumi G, Srinivasan J, Brea D, Iadecola C, Anrather J (2016) Spatio-temporal profile, phenotypic diversity, and fate of recruited monocytes into the post-ischemic brain. J Neuroinflammation 13:285.

Grassivaro F, Menon R, Acquaviva M, Ottoboni L, Ruffini F, Bergamaschi A, Muzio L, Farina C, Martino G (2020) Convergence between microglia and peripheral macrophage phenotype during development and neuroinflammation. J Neurosci 40:784-795.

Hagberg H, Mallard C, Ferriero D, Vannucci S, Levison S, Vexler Z, Gressens $\mathrm{P}$ (2015) The role of inflammation in perinatal brain injury. Nat Rev Neurol 11:192-208.

Herz J, Filiano AJ, Smith A, Yogev N, Kipnis J (2017) Myeloid cells in the central nervous system. Immunity 46:943-956.

Hu X, Li P, Chen J (2013) Pro: regulatory T cells are protective in ischemic stroke. Stroke 44:e85-e86.

Iadecola C, Anrather J (2011) The immunology of stroke: from mechanisms to translation. Nat Med 17:796-808.

Jordao MJ, Sankowski R, Brendecke SM, Locatelli YH, Tai TL, Tay E, Schramm S, Armbruster N, Hagemeyer O, Gross D, Mai O, Cicek T, Falk M, Kerschensteiner M, Grun D, Prinz M (2019) Single-cell profiling identifies myeloid cell subsets with distinct fates during neuroinflammation. Science 363:eaat7554.

Kono H, Rock KL (2008) How dying cells alert the immune system to danger. Nat Rev Immunol 8:279-289.

Kunis G, Baruch K, Rosenzweig N, Kertser A, Miller O, Berkutzki T, Schwartz M (2013) IFN-gamma-dependent activation of the brain's choroid plexus for CNS immune surveillance and repair. Brain 136:34273440.

Lalancette-Hebert M, Faustino J, Thammisetty SS, Chip S, Vexler ZS, Kriz J (2017) Live imaging of innate immune response in neonates reveals differential TLR-2 dependent activation patterns in sterile inflammation and infection. Brain Behav Immun 65:312-327.

Lalancette-Hebert M, Phaneuf D, Soucy G, Weng YC, Kriz J (2009) Live imaging of Toll-like receptor 2 response in cerebral ischaemia reveals a role of olfactory bulb microglia as modulators of inflammation. Brain 132:940-954.

Lazzaretto B, Fadeel B (2019) Intra- and extracellular degradation of neutrophil extracellular traps by macrophages and dendritic cells. J Immunol 203:2276-2290.

Li Q, Cheng Z, Zhou L, Darmanis S, Neff NF, Okamoto J, Gulati G, Bennett ML, Sun LO, Clarke LE, Marschallinger J, Yu G, Quake SR, Wyss-Coray T, Barres BA (2019) Developmental heterogeneity of microglia and brain myeloid cells revealed by deep single-cell RNA sequencing. Neuron 101:207-223. e210.

Liddelow SA, Temple S, Mollgard K, Gehwolf R, Wagner A, Bauer H, Bauer HC, Phoenix TN, Dziegielewska KM, Saunders NR (2012) Molecular characterisation of transport mechanisms at the developing mouse blood-CSF interface: a transcriptome approach. PLoS One 7:e33554.

Lu C, Liu L, Chen Y, Ha T, Kelley J, Schweitzer J, Kalbfleisch JH, Kao RL, Williams DL, Li C (2011) TLR2 ligand induces protection against cerebral ischemia/reperfusion injury via activation of phosphoinositide 3-kinase/Akt signaling. J Immunol 187:1458-1466.

Mallard C, Ek CJ, Vexler ZS (2018) The myth of the immature barrier systems in the developing brain: role in perinatal brain injury. J Physiol 596:5655-5664.

Mallard C, Tremblay ME, Vexler ZS (2019) Microglia and neonatal brain injury. Neuroscience 405:68-76.

Matsumoto S, Tanaka J, Yano H, Takahashi H, Sugimoto K, Ohue S, Inoue A, Aono H, Kusakawa A, Watanabe H, Kumon Y, Ohnishi T (2015) $\mathrm{CD} 200^{+}$and $\mathrm{CD}^{-} 00^{-}$macrophages accumulated in ischemic lesions of rat brain: the two populations cannot be classified as either M1 or M2 macrophages. J Neuroimmunol 282:7-20.

McColl SR, Clark-Lewis I (1999) Inhibition of murine neutrophil recruitment in vivo by CXC chemokine receptor antagonists. J Immunol 163:2829-2835

Mottahedin A, Joakim Ek C, Truve K, Hagberg H, Mallard C (2019) Choroid plexus transcriptome and ultrastructure analysis reveals a TLR2-specific chemotaxis signature and cytoskeleton remodeling in leukocyte trafficking. Brain Behav Immun 79:216-227. 
Mottahedin A, Smith PL, Hagberg H, Ek CJ, Mallard C (2017) TLR2-mediated leukocyte trafficking to the developing brain. J Leukoc Biol 101:297305

Nelson KB (2007) Perinatal ischemic stroke. Stroke 38:742-745.

Nelson KB, Lynch JK (2004) Stroke in newborn infants. Lancet Neurol 3:150-158

Planas AM, Gomez-Choco M, Urra X, Gorina R, Caballero M, Chamorro A (2012) Brain-derived antigens in lymphoid tissue of patients with acute stroke. J Immunol 188:2156-2163.

Prame Kumar K, Nicholls AJ, Wong CHY (2018) Partners in crime: neutrophils and monocytes/macrophages in inflammation and disease. Cell Tissue Res 371:551-565.

Prinz M, Priller J (2017) The role of peripheral immune cells in the CNS in steady state and disease. Nat Neurosci 20:136-144.

Raju TN, Nelson KB, Ferriero D, Lynch JK, NICHD-NINDS Perinatal Stroke Workshop Participants (2007) Ischemic perinatal stroke: summary of a workshop sponsored by the National Institute of Child Health and Human Development and the National Institute of Neurological Disorders and Stroke. Pediatrics 120:609-616.

Saederup N, Cardona AE, Croft K, Mizutani M, Cotleur AC, Tsou CL, Ransohoff RM, Charo IF (2010) Selective chemokine receptor usage by central nervous system myeloid cells in CCR2-red fluorescent protein knock-in mice. PLoS One 5:e13693.

Saunders NR, Dziegielewska KM, Mollgard K, Habgood MD (2018) Physiology and molecular biology of barrier mechanisms in the fetal and neonatal brain. J Physiol 596:5723-5756.

Saunders NR, Knott GW, Dziegielewska KM (2000) Barriers in the immature brain. Cell Mol Neurobiol 20:29-40.

Schwartz M, Baruch K (2014) The resolution of neuroinflammation in neurodegeneration: leukocyte recruitment via the choroid plexus. EMBO J 33:7-22.

Shechter R, Miller O, Yovel G, Rosenzweig N, London A, Ruckh J, Kim KW, Klein E, Kalchenko V, Bendel P, Lira SA, Jung S, Schwartz M (2013) Recruitment of beneficial M2 macrophages to injured spinal cord is orchestrated by remote brain choroid plexus. Immunity 38:555-569.

Shichita T, Ito M, Morita R, Komai K, Noguchi Y, Ooboshi H, Koshida R, Takahashi S, Kodama T, Yoshimura A (2017) MAFB prevents excess inflammation after ischemic stroke by accelerating clearance of damage signals through MSR1. Nat Med 23:723-732.

Souto FO, Alves-Filho JC, Turato WM, Auxiliadora-Martins M, Basile-Filho A, Cunha FQ (2011) Essential role of CCR2 in neutrophil tissue infiltration and multiple organ dysfunction in sepsis. Am J Respir Crit Care Med 183:234-242.

Stridh L, Smith PL, Naylor AS, Wang X, Mallard C (2011) Regulation of Toll-like receptor-1 and -2 in neonatal mice brains after hypoxia-ischemia. J Neuroinflammation 8:45.

Szmydynger-Chodobska J, Strazielle N, Gandy JR, Keefe TH, Zink BJ, Ghersi-Egea JF, Chodobski A (2012) Posttraumatic invasion of monocytes across the blood-cerebrospinal fluid barrier. J Cereb Blood Flow Metab 32:93-104.

Szmydynger-Chodobska J, Strazielle N, Zink BJ, Ghersi-Egea JF, Chodobski A (2009) The role of the choroid plexus in neutrophil invasion after traumatic brain injury. J Cereb Blood Flow Metab 29:1503-1516.

Van Hove H, Martens L, Scheyltjens I, De Vlaminck K, Pombo Antunes AR, De Prijck S, Vandamme N, De Schepper S, Van Isterdael G, Scott CL, Aerts J, Berx G, Boeckxstaens GE, Vandenbroucke RE, Vereecke L, Moechars D, Guilliams M, Van Ginderachter JA, Saeys Y, Movahedi K (2019) A single-cell atlas of mouse brain macrophages reveals unique transcriptional identities shaped by ontogeny and tissue environment. Nat Neurosci 22:1021-1035.

Vexler ZS, Mallard C, Hagberg H (2018) Positive and negative conditioning in the neonatal brain. Cond Med 1:279-293.

Wendland MF, Faustino J, West T, Manabat C, Holtzman DM, Vexler ZS (2008) Early diffusion-weighted MRI as a predictor of caspase-3 activation after hypoxic-ischemic insult in neonatal rodents. Stroke 39:18621868 .

Woo MS, Wang X, Faustino J, Derugin N, Wendland MF, Zhou P, Iadecola C, Vexler ZS (2012) Genetic deletion of CD36 enhances injury after acute neonatal stroke. Ann Neurol 72:961-970.

Wu R, Li X, Xu P, Huang L, Cheng J, Huang X, Jiang J, Wu LJ, Tang Y (2017) TREM2 protects against cerebral ischemia/reperfusion injury. Mol Brain 10:20.

Xia CY, Zhang Y, Gao ZZ, Wang NH Chen (2015) Selective modulation of microglia polarization to M2 phenotype for stroke treatment. Int Immunopharmacol 25:377-382. 